Article

\title{
Green Production of Glycerol Ketals with a Clay-Based Heterogeneous Acid Catalyst
}

\author{
Sondes Amri ${ }^{1,2,3}$, Jaime Gómez ${ }^{3}$, Ana Balea ${ }^{3}{ }^{\complement}$, Noemi Merayo ${ }^{3,4}\left(\mathbb{C}\right.$, Ezzeddine Srasra ${ }^{2}$, \\ Néji Besbes ${ }^{2}$ and Miguel Ladero ${ }^{3, * \mathbb{D}}$ \\ 1 Faculty of Sciences of Tunis, Tunis-Manar University, Tunis 2092, Tunisia; sondes_omri@yahoo.fr \\ 2 Laboratory Materials Composites and Clay Minerals, Group of Green and Applied Organic Chemistry, \\ National Center for Research in Materials Science, Borj Cerdia Technopole, Soliman 8027, Tunisia; \\ srasra.ezzedine@inrst.rnrt.tn (E.S.); besbesneji@yahoo.fr (N.B.) \\ 3 Department of Chemical Engineering and Materials, Faculty of Chemistry, Complutense University of Madrid, \\ 28040 Madrid, Spain; jaigom03@ucm.es (J.G.); anabalea@ucm.es (A.B.); nmerayoc@quim.ucm.es (N.M.) \\ 4 Department of Mechanical, Chemical and Industrial Design Engineering, ETSIDI, \\ Universidad Politécnica de Madrid, Ronda de Valencia 3, 28012 Madrid, Spain \\ * Correspondence: mladerog@ucm.es; Tel.: +34-91-394-4164
}

Received: 20 September 2019; Accepted: 16 October 2019; Published: 23 October 2019

\begin{abstract}
Glycerol remains a bottleneck for the biodiesel industry as well as an opportunity from the biorefinery perspective, having a notable reactivity as a platform chemical. In particular, glycerol ketals can be envisaged as oxygenates for fuel formulation. In this study, we have focused on the green synthesis of glycerol ketals by reacting glycerol with acyclic (acetone, butanone) and cyclic (cyclohexanone) ketones in the presence of an acid activated clay Tunisian AC in homogeneous systems under quasi-solventless conditions. These reactions were followed by on-line Fourier Transform Infrared Spectroscopy (FTIR) (namely, ReactIR 10). Firstly, the contacting time was selected studying the activity, stability and chemical characteristics of a set of catalysts. The 1-h activated clay AC was further characterized by X-Ray diffraction (XRD), Fourier Transform Infrared Spectroscopy (FTIR) and Scanning Electronic Microscopy with Energy Dispersive Spectroscopy (SEM/EDS). Finally, the effect of the main operational variables (catalyst concentration, reagents molar ratio, time and temperature) were checked and we reflected on adequate second-order kinetic models with partial first-order deactivation.
\end{abstract}

Keywords: clay; green synthesis; glycerol; ketone; ketals; oxygenated additives; catalyst

\section{Introduction}

With the advent of biorefineries, glycerol has become into a platform chemical, and not only a final product with a plethora of applications. In particular, new processes, or routes, and products are being sought for this polyol, while environmentally-friendly catalysts are created focusing on their simplicity on the one hand, and an enhanced selectivity and activity on the other. In the recent past, traditional industry usually used the homogeneous catalyst acids such as $\mathrm{H}_{2} \mathrm{SO}_{4}, \mathrm{HF}$ and $\mathrm{H}_{3} \mathrm{PO}_{4}$ for numerous processes [1,2]. However, homogenous acid catalysis is not environmentally friendly due to catalyst toxicity, its corrosive nature and its difficulty to be recycled [3], and need for further removal operation. For those reasons, their application is limited. Thereby, the proper choice of heterogeneous catalyst constitutes a major scientific challenge in organic chemistry, in particular for glycerol recycling and upgrading. Several studies have focused on the valorization of glycerol as a byproduct in biodiesel industry $[4,5]$, as it has attracted an appreciable attention.

Glycerol is an organic alcohol; an odorless, colorless and viscous liquid and it is fully miscible in water. It is mostly obtained from animal and plant sources by transesterification of triglycerides, 
their hydrolysis or by saponification processes conducted on them. This polyol has well known applications in many fields such as pharmaceutical which is used in toothpaste, mouthwashes or skin care products, food and beverage, tobacco, pulp and paper, leather, textile, detergent and explosive industries. Glycerol can also be transformed into high value-added products including polyethers, polycarbonates or alkyl resins. Moreover, due to its low toxicity and inflammability, it is exploited in medicinal applications [6]. Additionally, large quantities of glycerol are available as a reaction by-product because of the development of biodiesel production by transesterification of vegetable oils [7]. Numerous main pathways of glycerol transformation have been reported in literature involving hydrogenolysis [8], dehydration [9], oxidation [10], carbonation [5,11], etherification [12,13], esterification $[14,15]$, acetalization $[14,16]$ and ketalization $[17,18]$. Therefore, a considerable number of chemical intermediates and commodities can be obtained from glycerol through optimized catalytic routes, as shown in Figure 1 [19]. Glycerol acetals and ketals can be synthesized through the acid-catalyzed reaction of glycerol with aldehydes and ketones, respectively. Glycerol ketals are interesting as fuel additives (oxygenates) [20-22], fuel antioxidants [23] and as reactive oxygen species (ROS) scavengers able to act in-vitro and in-vivo [24]. Solketal, in particular, is known to reduce gum formation and particulate emissions, enhance fuel flow in cold conditions, improve stability towards oxidation, and boost octane number when it is added to gasoline, which contributes to reducing the environmental impact (the $\mathrm{LD}_{50}$ for fish is higher than $3100 \mathrm{ppm}$ for solketal, while for MTBE it is $1000 \mathrm{ppm}$ ) [25].

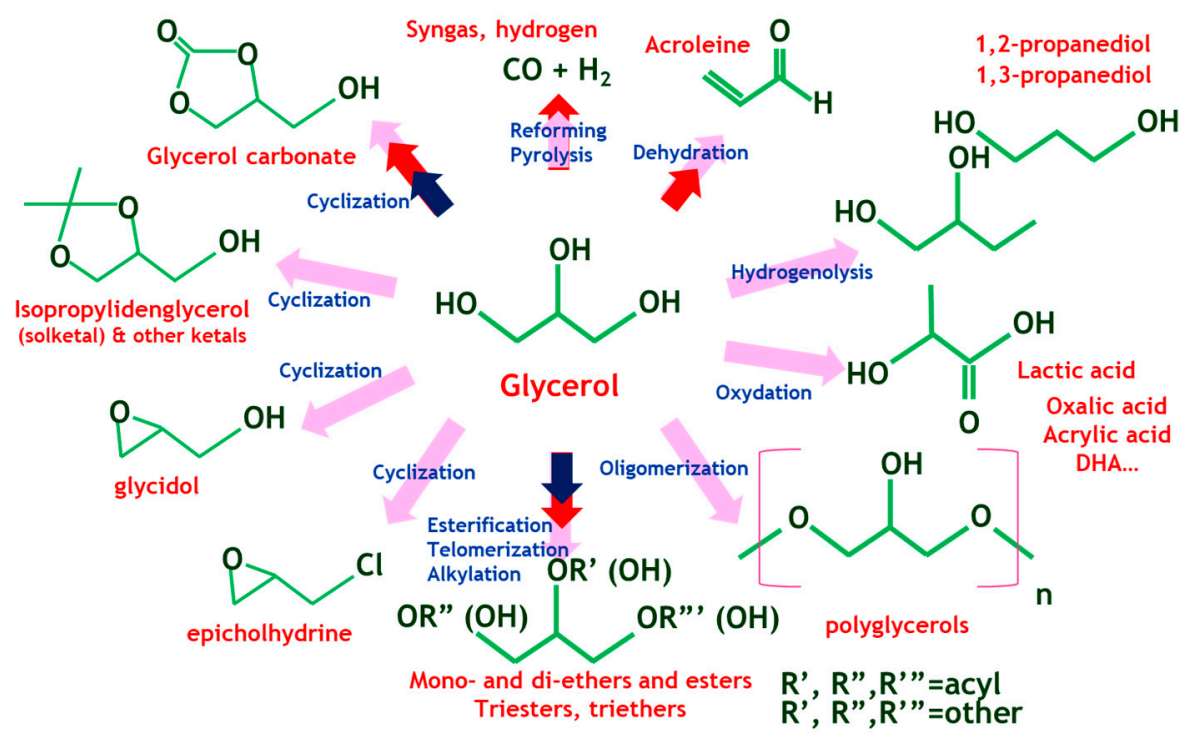

Figure 1. Several catalytic routes from glycerol (adapted from [19]).

Some heterogeneous catalysts that have been applied for the acetalization of glycerol are Amberlyst-46, Amberlyst-36 [26], Amberlyst-15 [27], beta-zeolite [28], montmorillonite [18], acidic clay supported heteropolycatalyst [29] and acidic VMCM-41 [6]. Within this context, we studied the application of acid-activated clay as a heterogeneous catalyst owing to easy external adsorption and desorption of chemicals during the reaction, its low price, the small effort to apply for its separation from the liquid media and its low environmental impact [30]. Clays and modified clays are widely included in chemical reactions such as synthesis and rearrangements of heterocycles, additions reactions, condensations reactions, Diels-Alders reaction, imine synthesis, epoxidation and several more $[29,31,32]$. In particular, solketal can be produced in a continuous-flow mode in fixed bed reactors [33] at laboratory and pilot-plant bench scales [34].

The aim of this work is to select and characterize an active acid-activated clay for an economic and ecological synthesis of ketals from glycerol with acetone, butanone and cyclohexanone under mild quasi-solventless reaction conditions, further studying the kinetics of such reacting systems. 


\section{Materials and Methods}

\subsection{Materials}

During the course of the experimental work, several reagents were employed (all of them purchased from Sigma-Aldrich, if another supplier is not indicated): extra pure glycerol (assay grade 99.88\%) from Fischer chemical; acetone (assay grade 99.88\%); butanone or methylethylketone. (MEK) (assay grade 99.88\%); cyclohexanone (assay grade 99.88\%); isopropanol (assay grade $99.88 \%$ ); acid activated clay AC as a catalyst; hydrochloric acid (reagent, purity $36 \%$ ). Liquid nitrogen was used to stabilize the on-line FTIR probe during calibrations and essays. The raw clay RC powder used in this work was obtained from the South-East region of Tunisia (Djebel Haidoudi-Gabes).

\subsection{Methods}

\subsubsection{Purification of Clay}

The natural clay powder used in this work was withdrawn from the center region of Gabes, the South-East of Tunisia [30-32]. The purification process of clay went through several unit operations starting by crushing using a mortar. Afterwards, the clay was diluted with distilled water and stirred for $24 \mathrm{~h}$ to complete mixture homogenization. It was subsequently decanted and washed several times with distilled water to remove all impurities. After cleaning, the support clay was dried in an oven at $100{ }^{\circ} \mathrm{C}$ for 2 days and, eventually, sieved to obtain a grain size fraction with a particle diameter lower than 100 microns.

\subsubsection{Activation of Clay Catalyst Powder}

In this process, the raw clay $\mathrm{RC}$ was activated by a cation exchange step using $\mathrm{HCl}$ solution $(3 \mathrm{~N})$ for at several contact time values from 0.5 to $20 \mathrm{~h}$. After drying at $80^{\circ} \mathrm{C}$, clay was washed with distilled water and centrifuged at 3500 r.p.m for $20 \mathrm{~min}$ to eliminate chlorides, carbonates and quartz until the $\mathrm{pH}$ was 6. After filtration, the acid activated clay (AC) was dried at $80^{\circ} \mathrm{C}$ during few days. Lastly, the dried solid of acid activated clay $\mathbf{A C}$ was powdered then kept away from moisture.

\subsubsection{Characterization of Clay Catalyst}

The crystalline structure of the raw clay RC and acid-activated clay $\mathrm{AC}$ was determined by the $X$-ray diffractometer (EMPYREAN), using CuKa1 radiation source $(\theta=1.540598 \AA$ ), all sample were scanned in the range of $5-79,984^{\circ}$ the $2 \theta$, the step size of $0.026^{\circ}$.

The morphologies of these solids were studied using scanning electronic microscopy (SEM) (SEM-JEOL-JSM6301-F) with an Oxford INCA/ Energy-350 microanalysis system. This apparatus was also used to investigate the elementary composition of the catalyst sample by energy-dispersive $\mathrm{X}$-ray spectroscopy (EDS) at a $133 \mathrm{eV}$ resolution.

To determine the main functional groups, FTIR spectra of the catalysts were recorded in the $4500-500 \mathrm{~cm}^{-1}$ wavenumber region using a Perkin-Elmer Spectrum 100 device.

The Brunauer-Emmett-Teller (BET) surface areas $\left(\mathrm{S}_{\mathrm{BET}}\right)$ were calculated from the corresponding nitrogen adsorption isotherms at 77K using micrometrics model, ASAP 2020, 700VA, volumetric analyzer. X-ray diffraction was used to investigate the X-ray diffraction patterns of the catalyst, mineral phase, and crystallinity before and after the acid activation process.

The cation exchange capacity (CEC) was determined by elemental microanalysis. The adsorption process was conducted according to Hagui et al. [35]. Briefly, $200 \mathrm{mg}$ of sample were contacted with $20 \mathrm{~mL}$ of an aqueous solution of ammonium acetate $(1 \mathrm{M})$ three times and was subsequently thoroughly washed with anhydrous methanol, firstly, and with Milli-Q water three times. Elemental microanalysis of nitrogen was finally performed with a LECO CHNS-932 equipment, ascribing all nitrogen to ammonium ions retained in the tested catalyst. CEC is expressed as milliequivalents per gram. 
A similar procedure was conducted for Brönsted acidity tests. In this case, $100 \mathrm{mg}$ of sample were added to $10 \mathrm{~mL}$ of a $10 \mathrm{~g} / \mathrm{L} \mathrm{KCl}$ aqueous solution, measuring $\mathrm{pH}$ with a Crison $22 \mathrm{GLP} \mathrm{pH}$ and ion meter until getting a stable reading (first measure) and for $24 \mathrm{~h}$ (second measure). Considering the released protons as strong acid available protons, Brönsted acidity was estimated in terms of millimols of protons per gram.

\subsubsection{Ketalization Reactions}

The reactions were carried out in glass reactor at atmospheric pressure. Typically, the glycerol (10 mmol), an adequate amount of ketone from 30 to $90 \mathrm{mmol}$ (acetone, butanone also known as methylethylketone or MEK, or cyclohexanone) and 2 to $4 \mathrm{~mL}$ isopropanol were mixed in a $25 \mathrm{~mL}$ round bottom flask till a clear homogeneous phase was obtained. After reaching the adequate temperature ( 25 to $50^{\circ} \mathrm{C}$, depending on the system under study), a certain mass of the acid-activated clay AC was added ( 0.25 to $3 \mathrm{~g}$, depending on the studied system) and stirred with a cylindrical magnetic stirrer to avoid catalyst attrition. The reactions of interest are shown in Figure 2.

a)

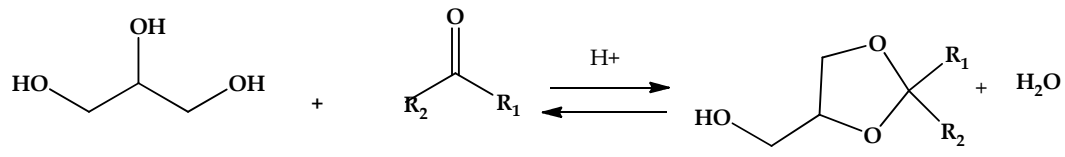

b)<smiles>CC(=O)[C@H](O)CC(O)CO</smiles>
c) но<smiles>CCC(=O)CC#CCOCC1COC(C)(CC)O1</smiles>

d) $\mathrm{HO}$<smiles>O=C1CCCCC1CO</smiles><smiles>C#C[C@H]1CCCC2(CC[C@@H](O)CO2)O1</smiles>

Figure 2. Reactions of acid-catalyzed of glycerol ketalization: (a) general ketalization; (b) System 1: ketalization of glycerol with acetone to 2,2-dimethyl-1,3-dioxolane-4-methanol (solketal or ketal 1); (c) System 2: ketalization of glycerol with MEK to 2-ethyl-2-methyl-1,3-dioxolane-4-methanol (ketal 2); (d) System 3: ketalization of glycerol with cyclohexanone to [1,4] dioxaspiro[4,5]decane-2-methanol (ketal 3).

Due to the low solubility of glycerol in the pure ketone, isopropanol was used as a cosolvent in the minimal amount needed to obtain a homogeneous system $(2.1 \mathrm{~mL}$ for acetone, $3.5 \mathrm{~mL}$ for MEK and $4 \mathrm{~mL}$ for cyclohexanone-higher amounts for more hydrophobic ketone). The reactions were monitored online with ReactIR 10 equipment (Mettler-Toledo, Columbia, SC, USA), based on FTIR spectroscopy, that is able to provide all the organic chemical species that are present in the solution as the reaction is being performed [36]. The FTIR spectrometer uses a mercury-cadmium telluride (MCT) detector that is cooled by liquid nitrogen and measurements are optically taken using a diamond-tipped probe with a $1.5 \mathrm{~m}$ long fiber-optic conduit. Data acquisition was performed from 2000 to $650 \mathrm{~cm}^{-1}$ with a $4 \mathrm{~cm}^{-1}$ nominal resolution. In Figure 3, an example of a reaction of acetone $(60 \mathrm{mmol})$ and glycerol (10 mmol), using isopropanol as cosolvent $(2.1 \mathrm{~mL})$ is shown (System 1$)$. In contrast, a blank using the aforementioned volume of isopropanol and the said molar amount of acetone is also presented. The signal at $1711 \mathrm{~cm}^{-1}$ wavenumber is selected in this case and in the other runs as it is an isolated 
peak in all FTIR spectra that can be used to follow the disappearance of any ketone (with some shift depending on the ketone under study). This peak is due to the $\mathrm{C}=\mathrm{O}$ stretch and its isolation can be easily perceived in Figure 4, where, as an example, all relevant FTIR spectra for the main components of system 1, with the exception of water, are displayed.

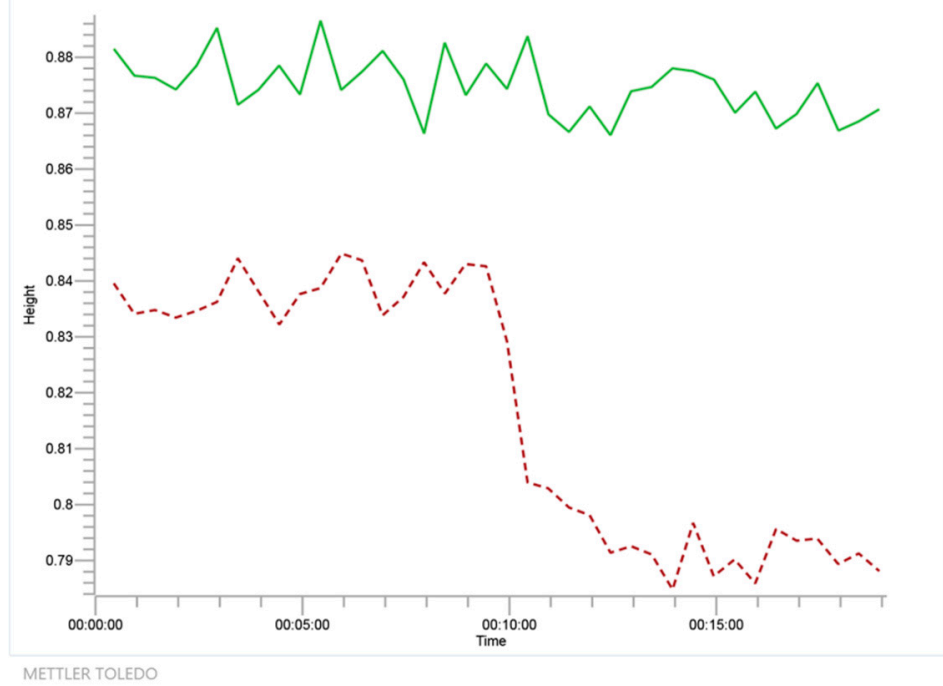

Figure 3. Time course as detected by Fourier Transform Infrared Spectroscopy (FTIR) at $1711 \mathrm{~cm}^{-1}$ wavenumber for the reaction of glycerol and acetone to solketal and water using isopropanol as solvent (system 1, in red dashed line) together with negative blank to show no reaction between isopropanol and acetone (in green solid line).

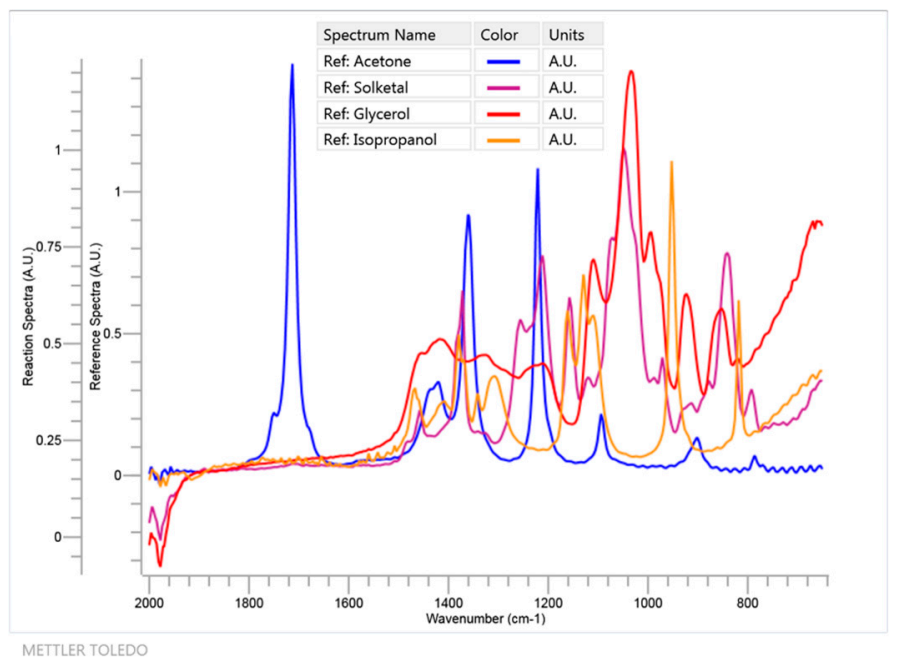

Figure 4. FTIR spectra in the $650-2000 \mathrm{~cm}^{-1}$ region for all relevant components of system 1 with the exception of water and isopropanol, which was added as a solvent to create and maintain a monophasic system during the ketalization process.

From Figure 3, it is evident that, while acetone disappears due to its reaction with glycerol, a polyol, no reaction is detected with isopropanol, probably due to the instability of the potential ketal and the steric hindrance due to the two methyl groups of the isopropanol molecule.

The most important variables affecting the reaction rate and final product yield (based on the ketone signal at time $t$ compared to ketone signal at time 0 , considering that all ketone was transformed to its corresponding ketal in a 1 to 1 molar relationship) were studied: temperature, molar ratio of reactants and catalyst concentration. Finally, the stability of the catalyst was assessed by repetitive 
reaction cycles. After each cycle, the catalytic solid was recovered, clean with acetone and dry at $110^{\circ} \mathrm{C}$ before the next reaction run.

\section{Results and Discussion}

\subsection{Catalyst Selection}

The smectite clay under study was contacted with $\mathrm{HCl}$ for different lengths of time, from 0.5 to $20 \mathrm{~h}$, and several key features were measured to select the most adequate contacting time. In Table 1, the yields after $24 \mathrm{~h}$ of reaction to solketal (ketal 1) and the ketal from cyclohexanone $\left([1,4]\right.$ dioxaspiro[4,5]decane-2-methanol or ketal 3), together with the specific surface $\left(\mathrm{S}_{\mathrm{BET}}\right)$ and the Brönsted acidity are displayed, while Table 2 depicts the mineralogical data of these clays treated during different times with $\mathrm{HCl} 3 \mathrm{~N}$. Finally, Figure 5 shows the initial reaction rate for the obtention of ketals 1 and 3 with fresh and used catalysts for the two reaction systems (systems 1 and 3).

Table 1. Key parameters of the catalysts obtained at several contacting time $\mathrm{HCl} 3 \mathrm{~N}$-smectite.

\begin{tabular}{ccccc}
\hline $\begin{array}{c}\text { Contacting Time } \\
\text { [h] }\end{array}$ & $\begin{array}{c}\text { 24 h Yield to } \\
\text { Ketal 1 [\%] }\end{array}$ & $\begin{array}{c}\text { 24 h Yield to } \\
\text { Ketal 3 [\%] }\end{array}$ & $\begin{array}{c}\mathbf{S}_{\text {BET }} \\
{\left[\mathbf{m}^{2} / \mathbf{g}\right]}\end{array}$ & $\begin{array}{c}\text { Brönsted Acidity } \\
{\left[\mathbf{m m o l ~ H}^{+} / \mathbf{g}\right]}\end{array}$ \\
\hline 0.5 & $68.2 \pm 2.8$ & $83.4 \pm 4.3$ & 125.4 & $(56 \pm 3.5) \times 10^{-4}$ \\
1 & $69.3 \pm 3.5$ & $85.3 \pm 5.1$ & 186.6 & $(65 \pm 5.1) \times 10^{-4}$ \\
2 & $68.1 \pm 3.2$ & $83.6 \pm 3.8$ & 225.4 & $(51 \pm 4.8) \times 10^{-4}$ \\
7 & $66.4 \pm 3.4$ & $81.8 \pm 4.2$ & 195.3 & $(38 \pm 2.4) \times 10^{-4}$ \\
20 & $63.3 \pm 3.4$ & $78.4 \pm 4.4$ & 170.4 & $(19 \pm 2.1) \times 10^{-4}$ \\
\hline
\end{tabular}

Table 2. Mineralogical characteristics of clays at several contacting times with $\mathrm{HCl} 3 \mathrm{~N}$ (EDS).

\begin{tabular}{ccccccc}
\hline $\begin{array}{c}\text { Contact } \\
\text { Time [h] }\end{array}$ & $\begin{array}{c}\mathrm{MgO} \\
\text { [molar \%] }\end{array}$ & $\begin{array}{c}\mathrm{C} \text { as } \mathrm{CO}_{2} \\
\text { [molar \%] }\end{array}$ & $\begin{array}{c}\mathrm{Al}_{2} \mathrm{O}_{3} \\
\text { [molar \%] }\end{array}$ & $\begin{array}{c}\mathrm{SiO}_{2} \\
\text { [molar \%] }\end{array}$ & $\begin{array}{c}\mathrm{K}_{2} \mathrm{O} \\
\text { [molar \%] }\end{array}$ & $\begin{array}{c}\mathrm{Fe} \text { as FeO } \\
\text { [molar \%] }\end{array}$ \\
\hline 0 & 1.3 & 54.5 & 11.9 & 25.4 & 0.7 & 1.2 \\
0.5 & 0.8 & 36.9 & 5.1 & 55.6 & 0.6 & 0.9 \\
1 & 0.3 & 37.3 & 4.7 & 55.3 & 0.8 & 1.2 \\
2 & - & 36.6 & 4.2 & 54.1 & 0.7 & 1.1 \\
7 & - & 38.6 & 2.5 & 58.4 & 0.5 & - \\
20 & - & 37.2 & 2.3 & 59.6 & 0.9 & - \\
\hline
\end{tabular}

Activity and stability tests were performed using acetone and cyclohexanone as ketones to obtain the corresponding ketals 1 and 3. Common conditions were the molar ratio ketone/glycerol, set at 6, and the catalyst concentration in all cases, set at $50 \mathrm{~g} / \mathrm{L}$. Due to the lower volatility of cyclohexanone, $40{ }^{\circ} \mathrm{C}$ was the temperature chosen for this reacting system, while $25^{\circ} \mathrm{C}$ were selected for acetone reactions. Therefore, the differences of initial reaction rate can be ascribed, at least partially, to the reaction temperature. Values of this variable, in Figure 5, indicate that the best contact time values are 0.5 and $1 \mathrm{~h}$, with a decrease in the activity for higher contact times. Stability was similar for all contact times. The difference comes between the two reacting systems: much more activity is maintained for the acetone system or system 1, probably because glycerol can be much easily washed in a more polar liquid reacting phase. It is interesting to observe that almost double isopropanol is needed when using cyclohexanone to obtain a homogeneous reacting system, with an increased probability that non-reacted glycerol (about a $20 \%$ of the initial one) adsorbs onto the tested clays, resulting in the subsequent deactivation by fouling [37].

However, as indicated in Table 1, after $24 \mathrm{~h}$ of reaction, the yield to the corresponding ketal is higher for cyclohexanone, and for the 0.5 and $1 \mathrm{~h}$ contact time catalysts with both ketones. Probably, the more stable structure of ketal 3 in comparison to ketal 1 (solketal) can be the reason for a higher yield of the former. Moreover, its molecular structure of ketal 1 probably sterically hinders the addition of a water molecule needed for the hydrolysis, so this later reaction, the reverse reaction, proceeds slowly 
in comparison to ketalization. As for the effect of the contacting time, although the porosity of the clay increases with the contact time up to a point, its Brönsted acidity markedly decreases after $1 \mathrm{~h}$ contact, with the concomitant reduction in activity. The effect of a strong acid on the clay, as it is well-known, is to dissolve several solid phases within the solid, starting by a reduction of the carbonate content (EDS data contained in Table 2). This solubilization process is fast, as the rich elemental composition present in the original smectite rapidly disappears in the 30-min acid activated clay, followed by a slower elimination of iron, magnesium, aluminum and potassium and the subsequent enrichment of the solid in quartz. This particular clay is rich in carbonate, as shown by EDS and by the basic $\mathrm{pH}$ value reached in the $\mathrm{KCl}$ test of acidity -almost $\mathrm{pH} 9.0-$, so $\mathrm{HCl}$ rapidly neutralized the superficial carbonate within the porous structure and beyond, creating a more intricate porous net and increasing the BET surface (up to $2 \mathrm{~h}$ ). Further contact time results in reduced BET surface, probably due to the dissolution of more solid and the increasing pore diameter. The disappearance of $\mathrm{Al}$ also reduces the clay natural Lewis acidity, but this phenomenon hardly affects catalyst activity, as condensation reactions (for example, esterification) are catalyzed by Brönsted acid sites [38].

Considering the activity and the stability of the clay catalysts in the ketalization of acetone and cyclohexanone with glycerol, it seems evident that the optimum time of smectite activation with $\mathrm{HCl}$ is $1 \mathrm{~h}$.

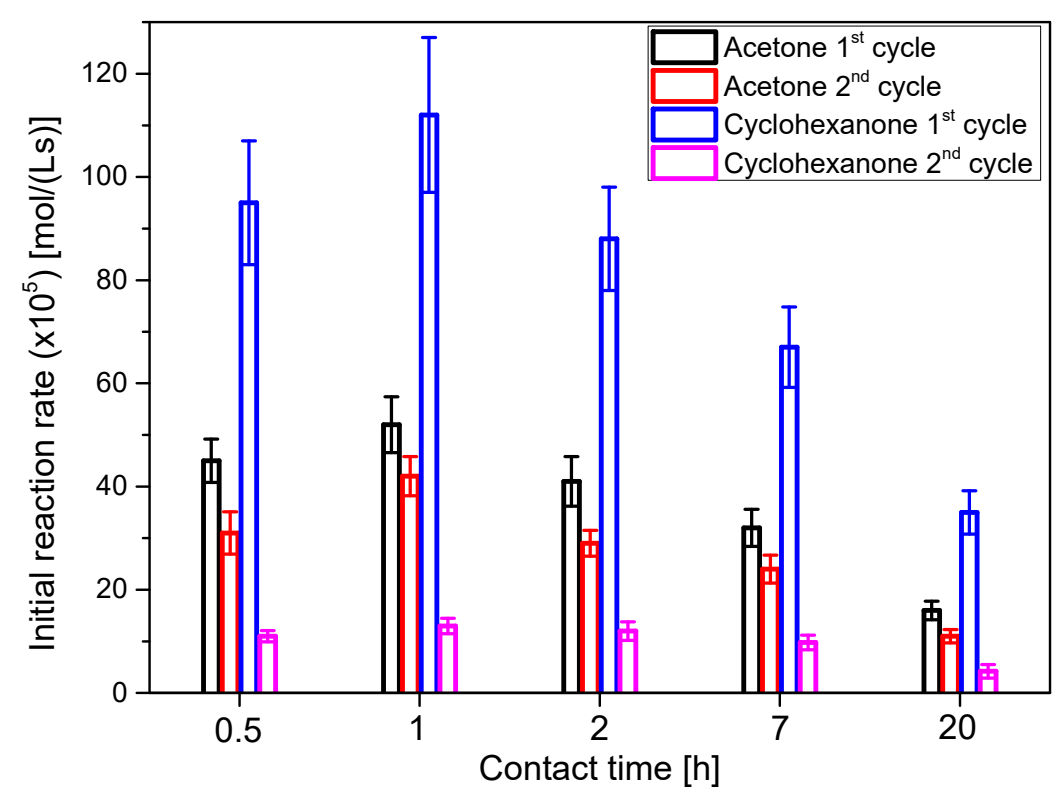

Figure 5. Initial reaction rate for runs with catalysts activated at several contact time with $\mathrm{HCl} 3 \mathrm{~N}$. Acetone-glycerol ketalization was performed at $25^{\circ} \mathrm{C}$, acetone/glycerol molar ratio of 6 and using $50 \mathrm{~g} / \mathrm{L}$ of the catalyst being tested. Conditions for cyclohexanone/glycerol ketalization were $40{ }^{\circ} \mathrm{C}$, the same molar ratio of cyclohexanone to glycerol and identical catalyst concentration as in the runs with acetone. The catalyst used for the first cycle was recovered, washed with acetone and dried at $100{ }^{\circ} \mathrm{C}$ for $24 \mathrm{~h}$ before using it for the second cycle.

\subsection{Further Characterization of the Selected Catalyst}

\subsubsection{XRD Studies}

The XRD pattern of the raw clay RC, in Figure 6A, shows an intense peak at 3.34 A that corresponds to quartz (Q), while those peaks at $\mathrm{d}=4.25,2.48,2.44$ and $2.27 \AA$ indicate the presence of both silica and quartz which are the major components of the clay. The pattern exhibits intensities at 3.83, 3.03, 2.08 and $1.8 \AA$, typical of carbonates as aragonite present in the clay which are the responsible for its original basic behavior, as shown by the $\mathrm{KCl}$ exchange measurements of Brönsted acidity or basicity. The diffractogram shows, in addition, peaks at $\mathrm{d}=6.49$ Å relative to kaolinite, which implies that 
this clay is heterogeneous. The presence of two distinct reflections at $\mathrm{d}_{001}=14.85 \AA(2 \theta=7)$ and $\mathrm{d}_{002}=4.25 \AA\left(2 \theta=24.89^{\circ}\right) 53 \AA$ permits to classify this clay as a smectite. The peaks at $4.48,2.57,2.55 \AA$ and $2.97 \AA$ reflect the presence of illite (I).

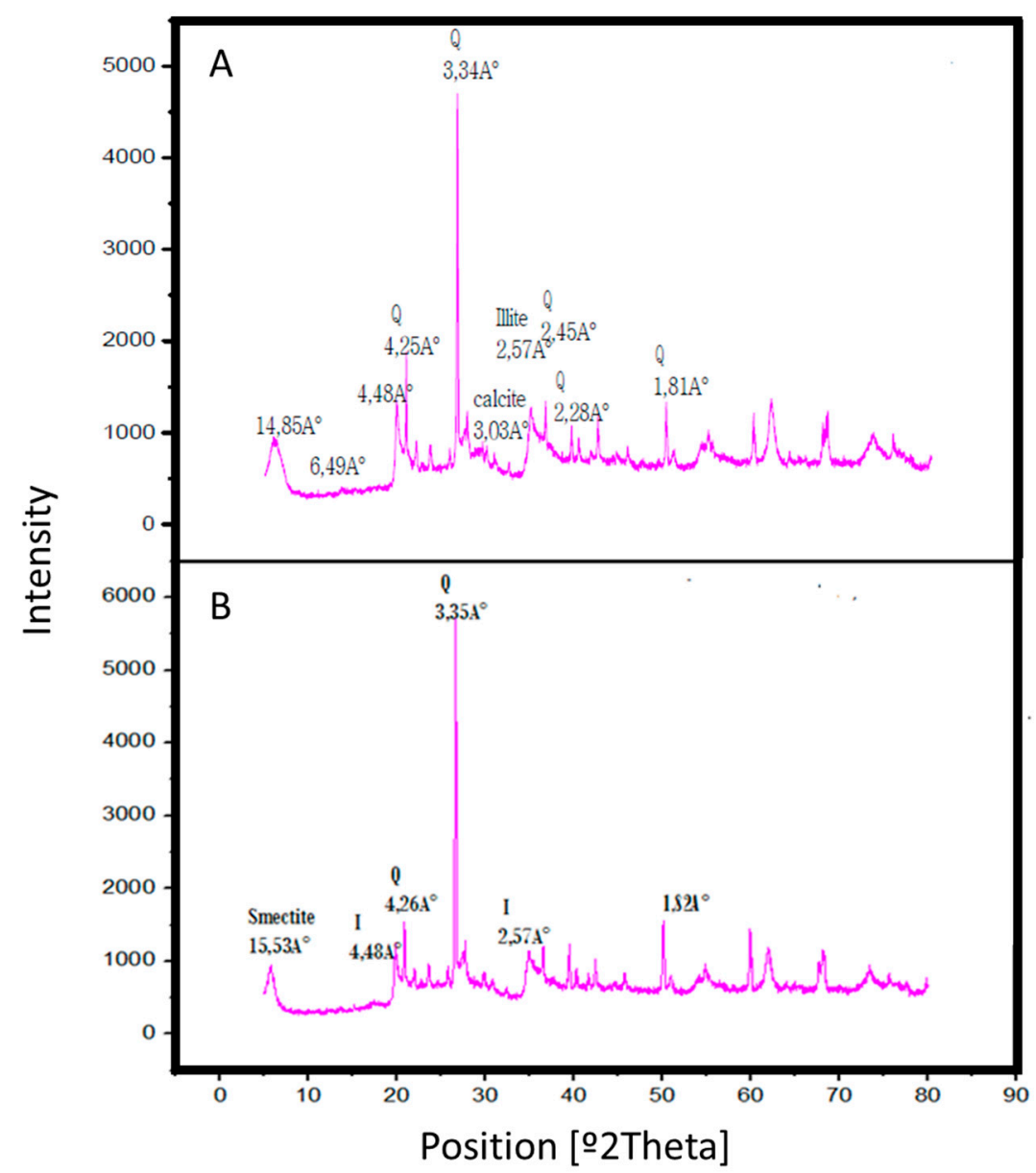

Figure 6. X-Ray diffraction (XRD) patterns of (A) raw clay RC and (B) acid activated clay AC with $\mathrm{HCl}$ $3 \mathrm{~N}$ for $1 \mathrm{~h}$.

The treatment of the raw clay $\mathrm{RC}$ during $1 \mathrm{~h}$ with $\mathrm{HCl} 3 \mathrm{~N}$ leads to the disappearance of some peaks (those at 6.49, 3.03, 2.45 and 2.28 $\AA$ ), as indicated in Figure 6B, which confirms the attack on the octahedral layer and the elimination of several mineral impurities, together with the removal of the cations from the octahedral layer, an aspect that creates a change in the interfoliar space. This elimination effect is evident at very short contact time (30 min), indicating that the acid attack is a fast process.

\subsubsection{FTIR Analysis}

FTIR spectrometry has been used to supplement other studies as it is a complementary technique to X-ray diffraction. Absorption bands at $1003 \mathrm{~cm}^{-1}$ and $3651 \mathrm{~cm}^{-1}$ are consistent with XRD, indicating the presence of kaolinite in clay. The band at $1626 \mathrm{~cm}^{-1}$ is attributable to the flexion of the $\mathrm{H}-\mathrm{OH}$ bonds of the structural water molecules and that at $907 \mathrm{~cm}^{-1}$ to the bending vibrations of the $\mathrm{Al}-\mathrm{Al}-\mathrm{OH}$ and $\mathrm{Al}-\mathrm{Mg}-\mathrm{OH}$ groups, indicating the presence of a smectite. Bands at $980 \mathrm{~cm}^{-1}$ (raw clay RC) and $1028 \mathrm{~cm}^{-1}$ ( $1 \mathrm{~h}$ acid treated clay AC) can be attributed to quartz (Si-O bonds). The simultaneous presence of the $3620 \mathrm{~cm}^{-1}$ and $912 \mathrm{~cm}^{-1}$ bands indicates that the smectite is dioctahedral. The band around $774 \mathrm{~cm}^{-1}$ indicates the presence of illite. These results are in agreement with those of the XRD. They confirm the presence of smectite, kaolinite and illite in the studied clay [29]. When comparing 
FTIR spectra A (raw clay RC) and B ( $1 \mathrm{~h}$ acid treated clay AC), in Figure 7 , the progressive disappearance of the signals corresponding to $\mathrm{Al}, \mathrm{Mg}$ and Fe ions (signals at 3621,1633 and $1428 \mathrm{~cm}^{-1}$ ) can be seen. This is also reflected in the EDS results in Section 3.1.

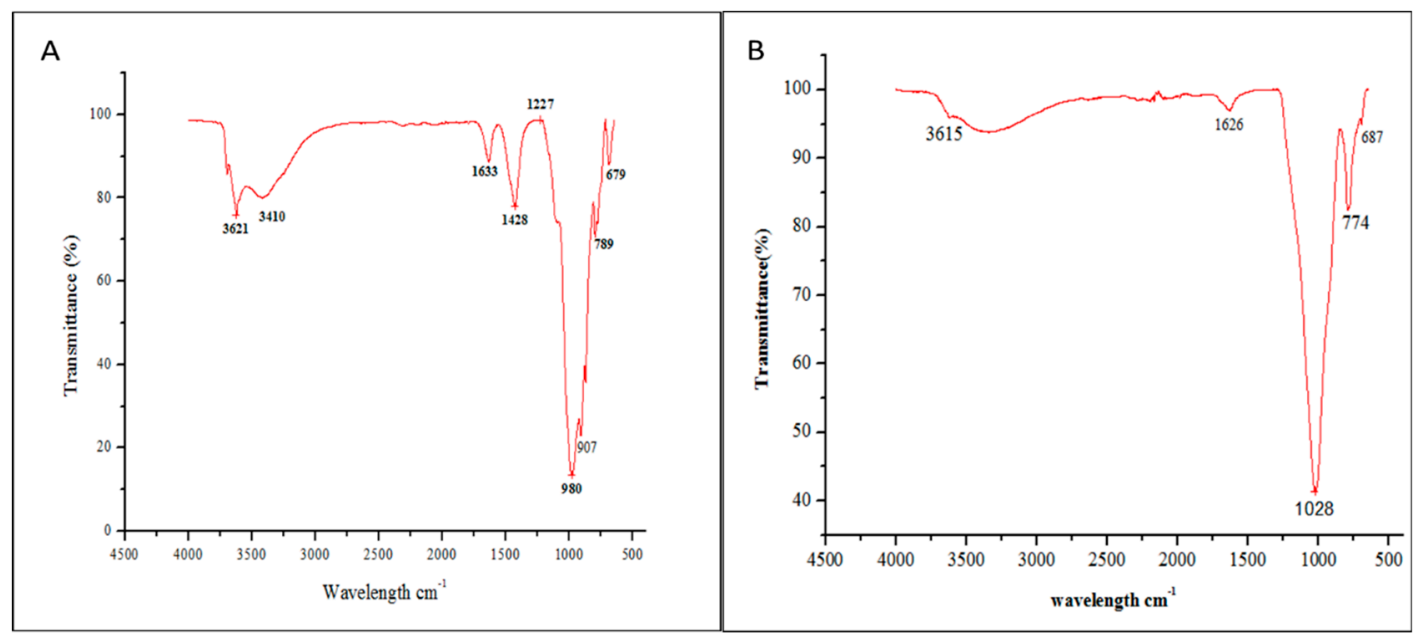

Figure 7. FTIR spectra of (A) raw clay RC and (B) acid activated clay AC with $\mathrm{HCl} 3 \mathrm{~N}$ for $1 \mathrm{~h}$.

\subsubsection{Microscopic Analysis SEM}

After a careful drying process due to the hygroscopic nature of the samples, SEM microscopy allows for the observation of the texture of the clay and the physical characterization of mineralogical assemblages. The images obtained by SEM of the clay with different magnifications are shown in Figure 8. Clay is in the form of fine aggregates and platelets in the form of rods. It can be seen in the poorly crystallized kaolinites and illites, as observed by Fatimah et al. [22]. The images are consistent with previous XRD results which show the presence of carbonates and quartz. Carbonates (calcite) are in the form of highly visible aggregates while quartz is in the form of small grains $[23,24]$. The images show a sheet structure of the clay. In Figure 8 A, with a magnification of 500x, the clay presents different grain sizes. With a magnification of 1000× (Figure 8B), an assembly of aggregates of different shapes and oriented towards different directions were observed. The magnification of our sample at 5000x (Figure 8C) shows that the clay has the form of exploded sheets.

Finally, CEC of the raw or crude clay RC and the 1-h acid treated clay AC were assessed, to find that this property was reduced with the acid treatment from $74 \pm 3$ mequiv/100 $\mathrm{g}$ of solid to $32 \pm 2$ mequiv/100 $\mathrm{g}$ of solid, probably due to an ion-exchange process during the acid attack [35].

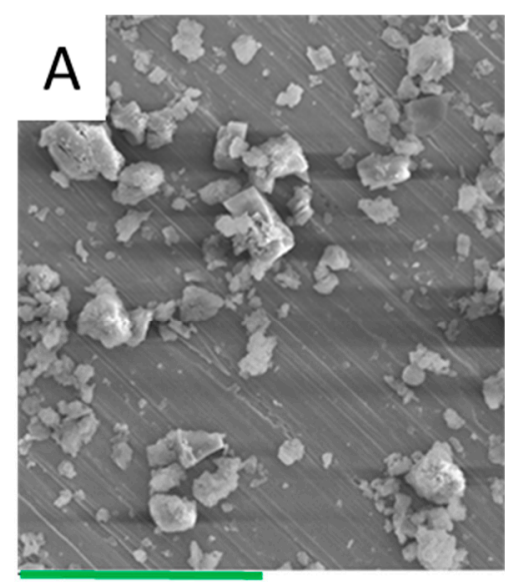

$100 \mu \mathrm{m}$

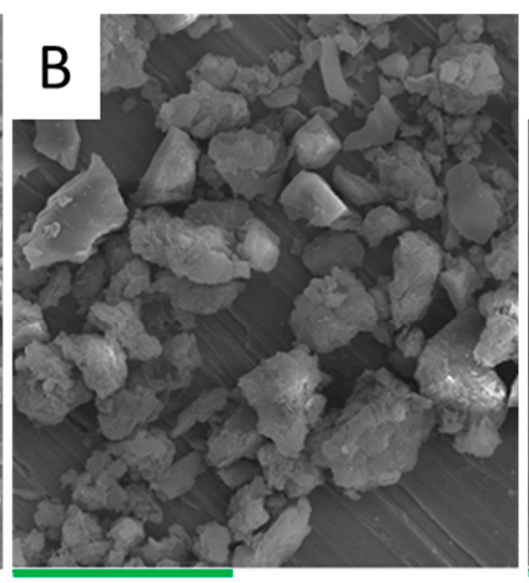

$50 \mu \mathrm{m}$

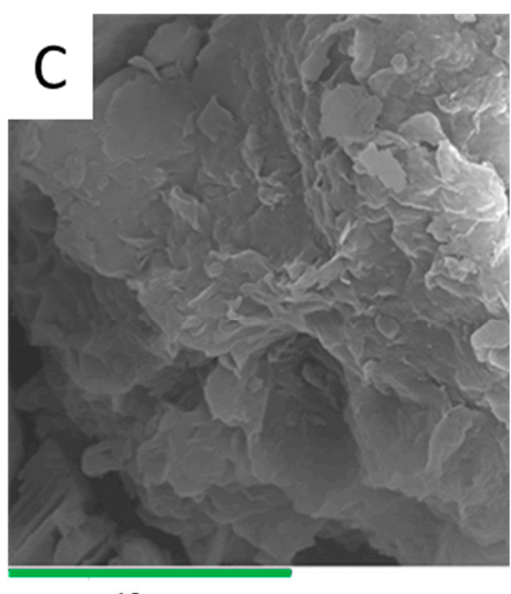

$10 \mu \mathrm{m}$

Figure 8. SEM micrographs at several magnifications of the $1 \mathrm{~h}$ acid-activated clay (AC). 


\subsection{Glycerol Ketalization Kinetic Studies}

The catalytic ketalization of glycerol with acetone (system 1), butanone or MEK (system 2) and cyclohexanone (system 3) under several conditions by changing the catalyst amount, the temperature and the molar ratio of ketone to glycerol were studied. To ensure a proper contact of the FTIR probe with the chemicals, the systems were completely homogenous by the action of isopropanol that acted as a cosolvent to avoid, in particular, any deposit of glycerol in the surface probe.

Experimental data were treated to calculate the concentration of ketal (by stoichiometry), the yield to this product (in particular, at the end of the chemical reaction, at $24 \mathrm{~h}$ ) and the initial rate, to perform a preliminary analysis and proposed a possible kinetic model. Afterwards, a kinetic model was proposed in view of the preceding results and it was fitted firstly to each run, to runs at different values of the process variables under study and, finally, to all data at the same time, to have a kinetic model able to explain the temporal evolution of each reacting system in all the experimental range under study. The fitting of the model was performed with Aspen Custom Modeler v10, using an algorithm for non-linear regression (NL2SOL) coupled to another algorithm to integrate the ordinary differential equations of the reaction rates (4th order Runge-Kutta algorithm). The model was assessed for each system in terms of physical adequacy (positive value of the constants and the activation energies and adequate range of values for these later) and statistical meaning (goodness-of-fit parameters with adequate values and narrow confidence intervals or standard errors for the kinetic parameters). The goodness-of-fit parameters were based on the Sum of Squared Residuals (SSR), which should be minimal, and were:

$$
\begin{aligned}
& S S R=\sum_{j=1}^{j=C_{i}} \sum_{i=1}^{=N}\left(C_{j n \exp }-C_{j n \text { calc }}\right) \\
& R M S E=\sqrt{\frac{S S R}{N-K}} \\
& F=\frac{\sum_{j=1}^{j=C} \sum_{n=1}^{n=N}\left(\frac{C_{j, \text { calc }}}{K}\right)^{2}}{\sum_{j=1}^{j=C} \sum_{n=1}^{n=N}\left(\frac{S S R}{N-K}\right)} \\
& V E(\%)=100\left(1-\frac{\sum_{l=1}^{L} S S Q_{l}}{\sum_{l=1}^{L} S S Q_{\text {mean }_{l}}}\right) .
\end{aligned}
$$

The parameter RMSE (Root of the Mean Squared Error), as the SSR should be minimum (ideally, zero), while the Fisher parameter $\mathrm{F}$ (computed at $95 \%$ confidence) should be maximal (ideally, infinitum). These parameters are computed using concentration, conversion or yield values, so they are integral by nature. However, the percentage of variation explained (VE) reflects how the model is able to explain the variations of those integral variables, as concentration, with time, so it reflects how the overall reaction rate computed with the model is able to explain the experimental reaction rate. Here, a $100 \%$ value means a $100 \%$ coincidence between the computed rate value and the experimental one.

\subsubsection{System 1: Ketalization with Acetone. Preliminary Analysis}

\section{Effect of Catalyst Concentration}

The effect of catalyst dosage on solketal yield was investigated by varying acid activated clay AC concentration, selecting the values 25,50 and $100 \mathrm{~g} / \mathrm{L}$ and keeping constant the other reaction parameters: $6 / 1$ acetone/glycerol molar ratio at room temperature $25^{\circ} \mathrm{C}$ for $24 \mathrm{~h}$. The yields to the ketal and the initial overall reaction rate are displayed in Figure 9. 


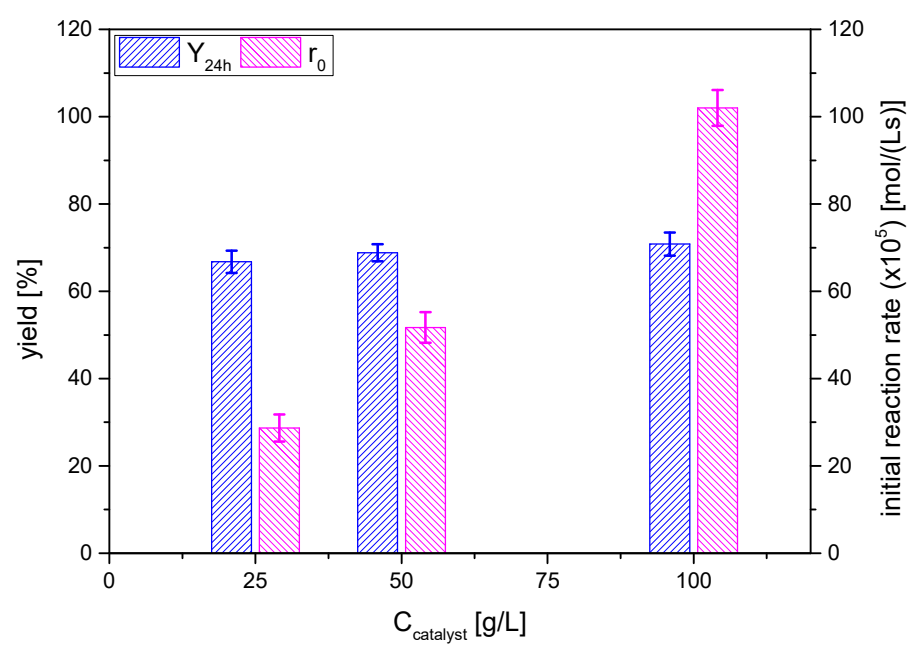

Figure 9. Effect of catalyst amount on the yield of solketal 1 in terms of the yield to the ketal 1 at $24 \mathrm{~h}$ and the initial reaction rate (reaction conditions: acetone/glycerol molar ratio, $6: 1$; temperature, $25^{\circ} \mathrm{C}$ ).

In absence of the catalyst, no solketal formation was observed. Solketal 1 yields were increased significantly and reached from 66 to $71 \%$ in the presence of 25 to $100 \mathrm{~g} / \mathrm{L}$ of catalyst, values that are notably higher than the one obtained in totally solventless conditions (biphasic system at zero time evolving towards a monophasic one) in the same acetone/glycerol molar ratio and temperature conditions: ca. 50\% [17].

In the work by Esteban et al. [39], several strong acid exchange resins were assessed for the ketalization of glycerol and acetone, with Lanxess Lewatit GF101 being the most active one. It has an acidity of $5.11 \mathrm{mmol} \mathrm{H}^{+} / \mathrm{g}$ and the catalyst concentrations studied were 5 and $10 \mathrm{~g} / \mathrm{L}$, attaining initial reaction rates of about $2.15 \times 10^{-4} \mathrm{~mol} /(\mathrm{L} \cdot \mathrm{s})$ with a catalyst load of $5 \mathrm{~g} / \mathrm{L}$ at $30^{\circ} \mathrm{C}$. In this case, the acid-activated smectite $\mathrm{AC}$, at $50 \mathrm{~g} / \mathrm{L}$ and $25^{\circ} \mathrm{C}$, with the same acetone to glycerol molar ratio, leads to an initial reaction rate value of $5.1 \times 10^{-4} \mathrm{~mol} /(\mathrm{L} \cdot \mathrm{s})$. If the initial reaction rates, in terms of TOF (turnover frequency), are calculated, referring to the real concentration of strong acid sites per gram of solid, the values are $2.15 \times 10^{-4} \mathrm{~mol}_{\mathrm{ketal}} /\left(\mathrm{L} \cdot \mathrm{mmolH}^{+}\right)$for the benchmark biphasic system and the strong acid resin, and $1.56 \times 10^{-2} \mathrm{~mol}_{\mathrm{ketal}} /\left(\mathrm{L} \cdot \mathrm{mmolH}^{+}\right)$for the monophasic system and the acid-treated clay here reported. These results indicate an apparent TOF of the clay AC under study $\sim 75$ times higher. The small particle diameter of the clay-50 to $100 \mu \mathrm{m}$-means that is probable that no internal mass transfer hindrance exists, as was the case with the acid resin used of the reference kinetic study (approx. $100 \mu \mathrm{m})$. Therefore, although it remains to be studied, the difference should be allocated to the different nature of the support surface; for example, a less hygroscopic nature of the clay in comparison to the resin would lead to a more adequate distribution of reactants and products on the support surface. This hypothesis could explain the evident shift of the equilibrium towards the products when using clay AC: more water is expelled from the clay surface compared to strong acid exchange resins.

Apart from the comparison to strong acid exchange resins, the evolution of the reaction rate value with the concentration of the catalyst is linear, as expected for Brönsted acid catalysts with a good contact between the active sites and the reagents molecules. Therefore, the partial order to be considered in any rate equation for the catalyst concentration should be one (first order).

\section{Effect of Temperature}

The effect of the reaction temperature was investigated at three different, and moderate, temperatures from $25^{\circ} \mathrm{C}$ to $35^{\circ} \mathrm{C}$ as shown in Figure 10 . 


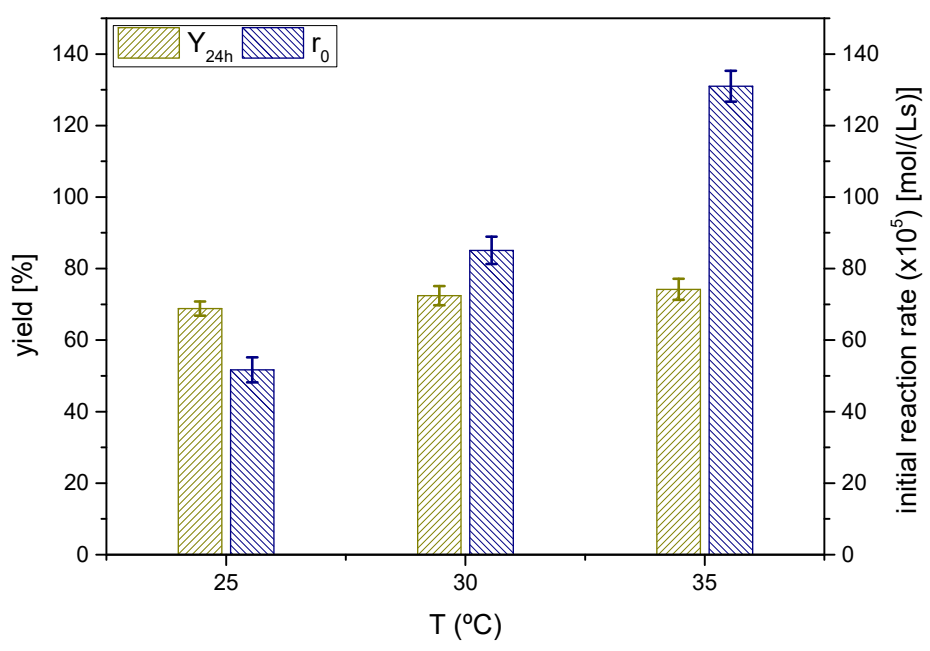

Figure 10. Influence of the reaction temperature on the yield of solketal 1 at $24 \mathrm{~h}$ and the initial reaction rate (Reaction conditions: acetone/glycerol molar ratio, 6:1; temperature, $25^{\circ} \mathrm{C}$ ).

The yields at equilibrium of the ketal 1 or solketal were slightly lower as the temperature decreased, showing that temperature shifts minimally from the equilibrium position towards the products. Thus, the process is slightly endothermal or even thermoneutral, considering the experimental error. Again, the yield at equilibrium is approximately $70 \%$. From a kinetics perspective, the initial reaction rate increases with temperature, following an exponential trend, not too steep, so the activation energy of the direct reaction (from glycerol and acetone to the ketal 1) should be moderate.

\section{Effect of Initial Molar Ratio of Reactants}

One of the classical strategies to shift the equilibrium position towards the products is to increase the molar excess of one reagent [17]. In this case, due to the interest in the full conversion of glycerol and the easy recovery of acetone, the acetone excess was studied. Therefore, three runs (in duplicate, as it has been the usual way in this work) were performed, selecting the acetone/glycerol molar ratio values of 3, 6 and 9. As shown in Figure 11, the yield to solketal increased from $\sim 65$ up to $\sim 75 \%$ when the excess of acetone increased from 3 to 9 ; in fact, fitting yields to a rectangular hyperbola permits us to conclude that increasing acetone excess up to infinitum will not totally shift the equilibrium position towards the products (the equilibrium position at infinite acetone seems to be $92 \%$, approximately). This fact could be explained if deactivation of the catalyst AC is present, as has been shown in the catalyst selection (Section 3.1).

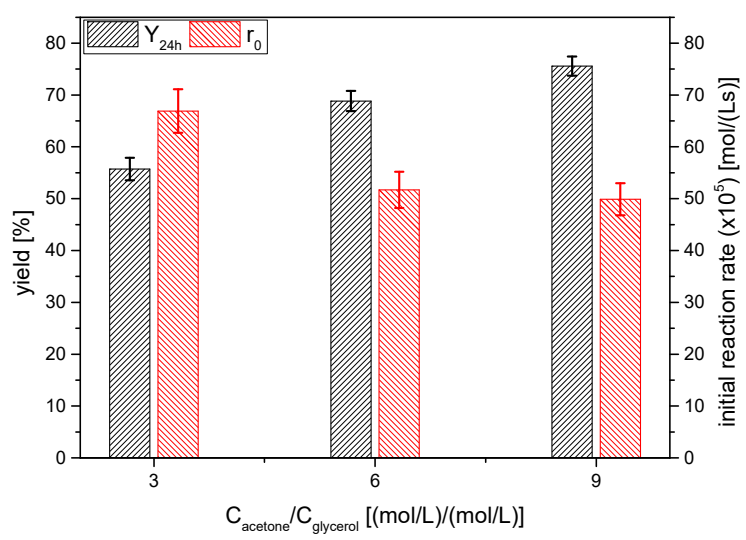

Figure 11. Influence of the molar excess of acetone on the yield of solketal 1 at $24 \mathrm{~h}$ and the initial reaction rate (Reaction conditions: acetone/glycerol molar ratio, $6: 1$; temperature, $25^{\circ} \mathrm{C}$ ). 
If we considered the product of the concentrations of the reagents, the initial reaction rate does not seem to be proportional to it, as $r_{0}$ should be approximately similar for the 3 and 6 acetone excess and about $15 \%$ lower for an excess of acetone of 9 . Therefore, at least at the beginning of the reaction process, the reaction is not an elemental one, as it is well-known, as a hemiketal-like intermediate is firstly formed and, subsequently, it cycles to form the ketal 1.

3.3.2. Systems 2 and 3: Ketalization with Butanone -MEK- and Cyclohexanone. Preliminary Analysis

\section{Effect of Catalyst Concentration}

The effect of the catalyst $\mathrm{AC}$ concentration on the initial reaction rate (that is, the rate of the ketalization reaction) is linear in both systems, as can be seen in Figure 12. The direct comparison to system 1 is not totally feasible, as these runs were performed at $40^{\circ} \mathrm{C}$, because the ketones are not as volatile as acetone, but it can be said that cyclohexanone has a reactivity similar to that of acetone: $\mathrm{r}_{0}$ at $35^{\circ} \mathrm{C}$ and $50 \mathrm{~g} / \mathrm{L}$ catalyst is about $1.02 \times 10^{-3} \mathrm{~mol} /(\mathrm{L} \cdot \mathrm{s})$ for acetone and this same parameter at $40^{\circ} \mathrm{C}$ approaches $1.2 \times 10^{-3} \mathrm{~mol} /(\mathrm{L} \cdot \mathrm{s})$. On the other hand, it is evident that the reaction rate is much lower for MEK than for the other two ketones, resulting in the need of more catalyst (from 100 to $300 \mathrm{~g} / \mathrm{L}$ ) to reach similar reaction rates. As the acidity and mass transfer is identical in all cases, this fact may be due to a worse distribution of MEK on the catalyst surface, probably displacing glycerol from it, by its adsorption onto the surface via the hydrophobic backbone of its $C 4$ chain.

The yields at equilibrium positions for butanone are similar than those for acetone $(\sim 70 \%)$, while the values are higher for cyclohexanone (near 85\%), suggesting a higher displacement of water in system 3 in comparison to the other systems (Figure 12).
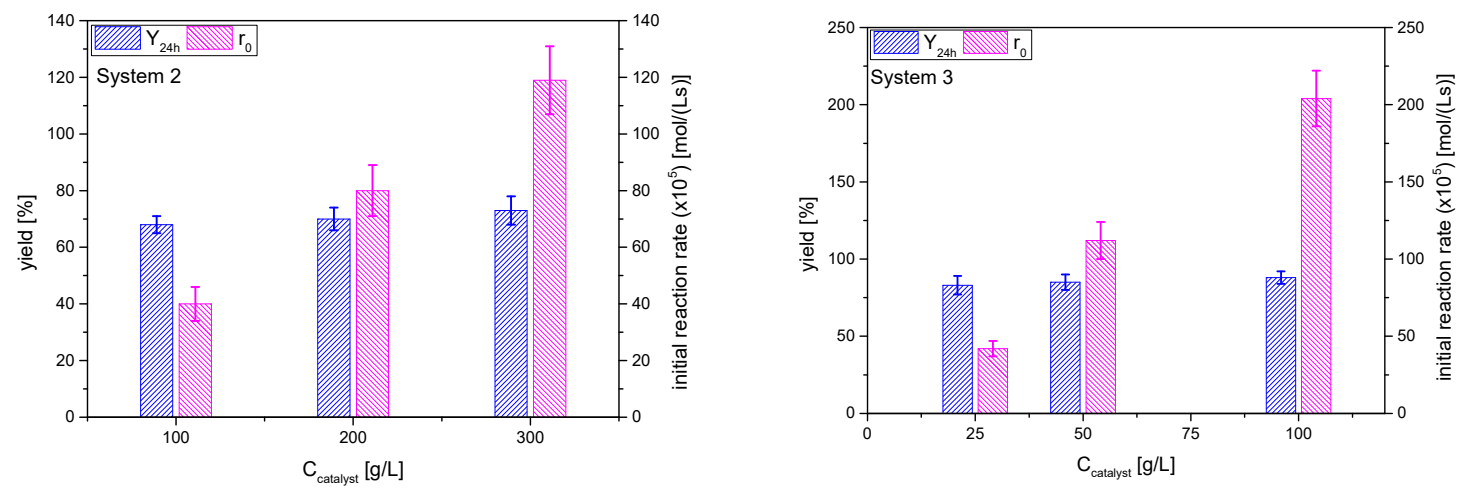

Figure 12. Effect of catalyst amount on the yield of ketals 2 and 3 at $24 \mathrm{~h}$ and the initial reaction rate (Reaction conditions: butanone/glycerol or cyclohexanone:glycerol molar ratio, $6: 1$; temperature, $40{ }^{\circ} \mathrm{C}$ ).

\section{Effect of Temperature}

As in the previous sections, yields of ketals 2 and 3 at $24 \mathrm{~h}$ and initial rates for the ketalization reaction are shown in Figure 13. It can be appreciated that the temperature affects the ketalization initial rate in an exponential manner (Arrhenius). The effect on $r_{0}$ is more pronounced for cyclohexanone, seemingly with a higher activation energy than the MEK-glycerol ketalization.

If the yields at different temperature values in both systems are considered, it seems that temperature scarcely affects the equilibrium position for MEK, but the yield to ketal 3, the case of cyclohexanone, is reduced with temperature. Therefore, as in the solketal case, the ketalization reaction of MEK and glycerol seems to be thermoneutral, whereas the same reaction for cyclohexanone appears to be slightly exothermic. Therefore, depending on the ketone, these processes can be either slightly endothermic or exothermic [40,41]. 

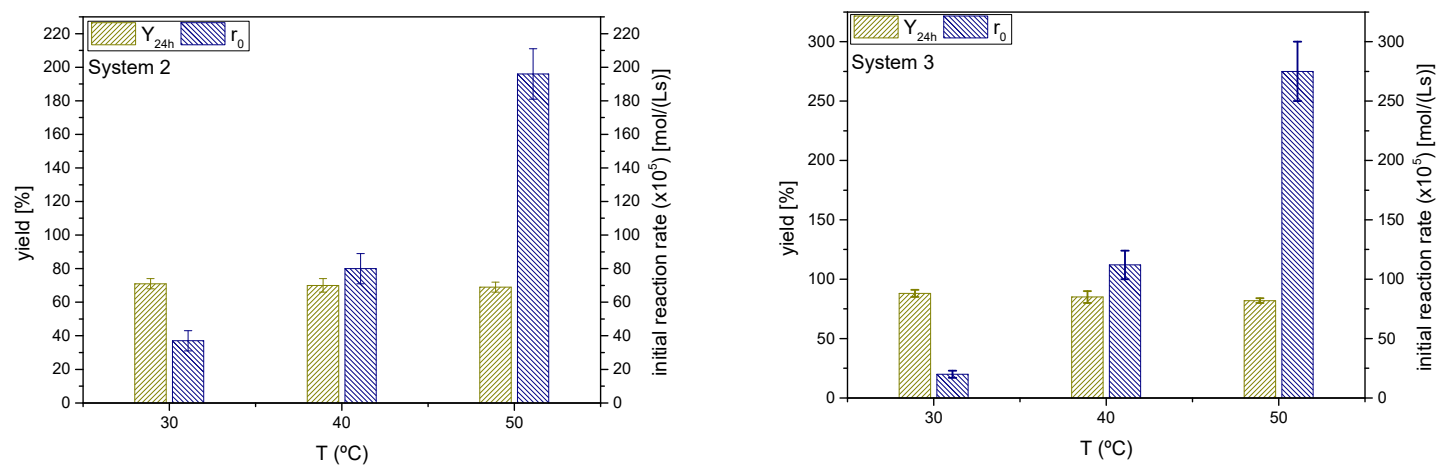

Figure 13. Influence of the reaction temperature on the yield of ketals 2 and 3 at $24 \mathrm{~h}$ and the initial reaction rate (Reaction conditions: butanone/glycerol or cyclohexanone:glycerol molar ratio, 6:1; temperature, $40^{\circ} \mathrm{C}$ ).

\section{Effect of Initial Molar Ratio of Reactants}

The influence of molar ratio of the ketones to glycerol resulted in yields to the corresponding ketals 2 and 3 at $24 \mathrm{~h}$ and initial reaction rates that are displayed in Figure 14. The overall trend in the initial reaction rate as the excess of the ketone increases is not clear, but it is decreasing somewhat, as can be expected when the product of the reagents concentrations is reduced by $14 \%$. The effect on the ketal yield with increasing ketone excess, as expected, is the increment of this parameter. Fitting yields at equilibrium to rectangular hyperbolas resulted, as in the case of solketal, in a value lower than 100\% (about 92-95\%), showing that the complete shift of the equilibrium towards the products is not possible, supporting in this way the hypothesis of deactivation, a phenomenon that happens, at least, when using strong acid exchange resins [39].
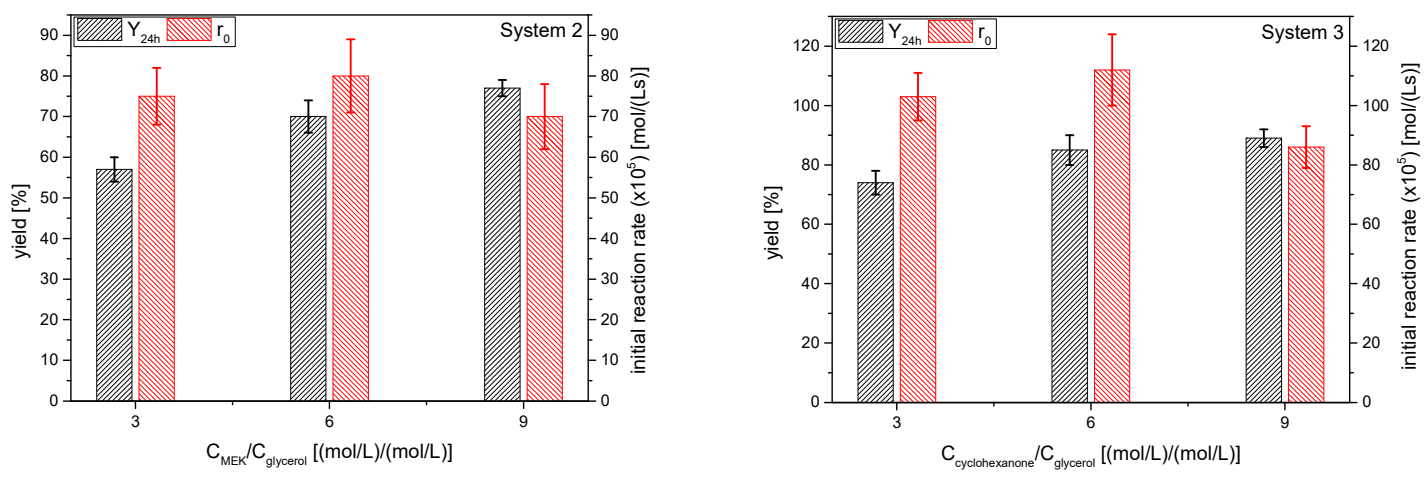

Figure 14. Influence of the ketone excess on the yield of ketals 2 and 3 at $24 \mathrm{~h}$ and the initial reaction rate (Reaction conditions: butanone/glycerol or cyclohexanone:glycerol molar ratio, 6:1; temperature, $40{ }^{\circ} \mathrm{C}$ ).

\subsubsection{Reutilization of the Catalyst}

To check how the catalyst $\mathrm{AC}$ is deactivated during ketalization, and considering that the majority of ketal production happened in the first hour, several short reaction cycles of 50 min were performed for all systems. The results, in terms of initial reaction rate (ketalization), are collected in Figure 15. The evolution of $r_{0}$ between cycles indicates that the catalyst deactivates following an exponential trend towards a stable, but less active, catalytic species. Though less evident, it happens also in other ketalization systems, where the catalyst seems to be less prone to deactivation, but, again, a certain stabilization is observed after a few cycles [35]. This behavior is typical of a heterogeneous catalyst that contains two or more types of active centers with different stabilities or catalysts that are partially blocked during the reaction process [42,43]. 


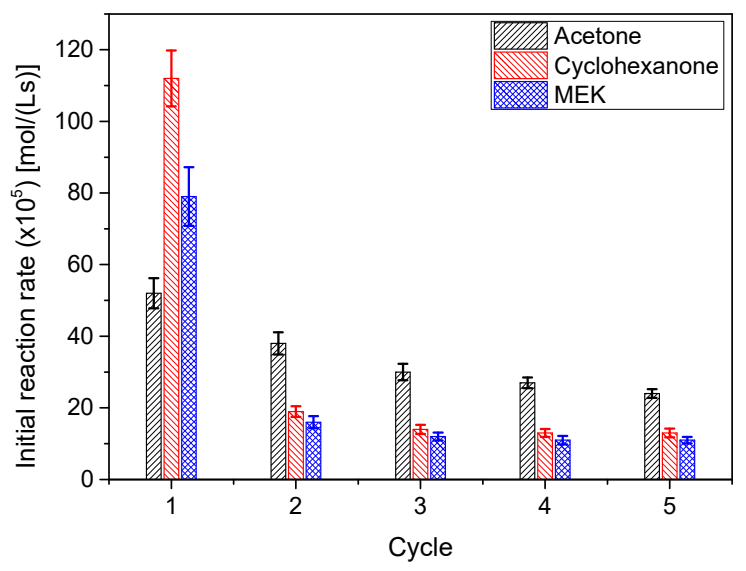

Figure 15. Evolution of the initial ketalization rates for all systems in subsequent reutilization cycles (System 1: acetone; System 2: butanone or methylethylketone (MEK); System 3: cyclohexanone). Reaction conditions: $25^{\circ} \mathrm{C}, 50 \mathrm{~g} / \mathrm{L}$ catalyst $\mathrm{AC}$ (system 1 ); $40{ }^{\circ} \mathrm{C}, 200 \mathrm{~g} / \mathrm{L}$ catalyst $\mathrm{AC}($ system 2$) ; 40{ }^{\circ} \mathrm{C}$, $50 \mathrm{~g} / \mathrm{L}$ catalyst AC (system 3); ketone/glycerol molar ratio $=6$ (all systems).

If the three systems under study are compared, it is also evident that chemicals in system 1 are less deleterious to the catalyst activity than those of the other two systems. As the difference is due to the ketone and the ketal in each of the systems and blockage is a possible deactivation mechanism, it could be guessed that ketones and ketals are more prone to remaining in the solid surface for systems 2 and 3 during the acetone washing processes after each cycle. This type of behavior is also observed with strong acid exchange resins for the first system (solketal or ketal 1) [39].

\subsubsection{Kinetic Model Fitting}

Considering the previous results, it is evident that a kinetic model with a direct reaction (ketalization) and a reverse reaction (hydrolysis) is needed. The results of the reuse of all catalysts reported in Section 3.1, at any contact time, suggest a deactivation process for systems 1 and 3. In the literature, for solketal and other ketals, kinetic models of the type Potential, Langmuir-HinshelwoodHougen-Watson (LHHW) and Eley-Rideal (ER) are proposed and fitted to the results $[17,40,41]$.

In this case, and for all systems, we have proposed and fitted a potential model considering that reactions are almost elemental (that is, the closing and opening reactions of the ketals are supposed to be very fast in comparison to reactions needing the collision of reagent molecules). This is in agreement with all kinetic models in literature, as far as we know, as, even in the hyperbolic models, the numerator always present terms for the direct and the reverse reactions that are first-order with respect to ketones and alcohols, on one side, and to ketals and water, on the other, with no term accounting for the presence of the intermediate.

Considering the deactivation of the catalyst during the chemical process, and given the results in the previous section, a first-order kinetic equation with remaining activity at infinitum time (partial deactivation) is proposed and coupled to the previous kinetic equation proposed for the ketalization and hydrolysis reactions. Therefore, the proposed kinetic model is:

$$
\begin{gathered}
r_{1}=k_{1} \cdot C_{\text {catalyst }} \cdot C_{\text {ketone }} \cdot C_{\text {glycerol }} \\
r_{2}=k_{2} \cdot C_{\text {catalyst }} \cdot C_{\text {ketal }} \cdot C_{\text {water }} \\
C_{\text {catalyst }}=\beta+(1-\beta) \cdot e^{-k_{d} \cdot t}
\end{gathered}
$$

where the first rate equation corresponds to the ketalization (direct) reaction and the second one to the hydrolysis. Equation (6) reflects in an integral mode the evolution of the catalyst activity because, although it is a first-order process, this process only affects a part of the activity present at zero time, 
which is $(1-\beta)$ if total activity is 1 and remaining activity at infinitum time is $\beta$. Constants $k_{1}$ and $k_{2}$ are second-order constants, while $\mathrm{k}_{\mathrm{d}}$ is a first-order constant.

As indicated at the beginning of this section devoted to results and their discussion, the proposed kinetic model was fitted, for each system, to each run, to runs where one of the variables was changed and to all runs at the same time. Results of this last fitting for all systems are collected in Tables 3 and 4 and in Figures 16-18. Table 3 collects statistical parameters related to the goodness of the fit of the model to all data for each system. In all cases, the values of SSR and RMSE are really low, given the high number of data $(\mathrm{N})$, indicating a close fit of the model to all data (this can be even better observed in the figures). Again, very high values of Fisher F at $95 \%$ confidence, much higher than the threshold values at that level of confidence (typically in the range 20-100) show that the model is adequate, so the hypotheses behind it seem acceptable, and the fit of the model to data for any of the systems is correct. Finally, the percentage of variation explained (VE) is near 100\%, so, again the predicted temporal evolution rate for the ketal is very similar to the experimental one.

Table 3. Goodness-of-fit parameters for the kinetic model for acetone (system 1), MEK or butanone (system 2) and cyclohexanone (system 3) ketalization reactions with glycerol.

\begin{tabular}{lccc}
\hline Parameter & System $\mathbf{1}$ & System 2 & System 3 \\
\hline $\mathrm{N}$ & 1869 & 2880 & 2404 \\
$\mathrm{~K}$ & 7 & 7 & 7 \\
$\mathrm{DF}$ & 1862 & 2873 & 2397 \\
SSR & 1.53 & 0.904 & 1.533 \\
RMSE & 0.0292 & 0.0198 & 0.0175 \\
F-value & 138,148 & 423,794 & 323,899 \\
VE (\%) & 98.86 & 98.26 & 99.41 \\
\hline
\end{tabular}

Table 4. Kinetic parameters for the model fitted to all data from acetone (system 1), MEK (system 2) and cyclohexanone (system 3) ketalization reactions with glycerol.

\begin{tabular}{lccc}
\hline Parameter & System $\mathbf{1}$ & System $\mathbf{2}$ & System $\mathbf{3}$ \\
\hline $\mathrm{Ln} \mathrm{k}_{01}$ & $12.61 \pm 0.25$ & $27.61 \pm 0.8$ & $12.88 \pm 0.13$ \\
$\mathrm{E}_{\mathrm{a}} / \mathrm{R}\left(\mathrm{k}_{1}\right)$ & $7869 \pm 77$ & $12,665 \pm 25$ & $8477 \pm 43$ \\
$\mathrm{Ln} \mathrm{k}_{02}$ & $15.65 \pm 0.72$ & $36.70 \pm 0.68$ & $20.12 \pm 0.19$ \\
$\mathrm{E}_{\mathrm{a}} / \mathrm{R}\left(\mathrm{k}_{2}\right)$ & $8497 \pm 214$ & $15,487 \pm 223$ & $10,446 \pm 61$ \\
$\mathrm{Ln} \mathrm{k}_{0 \mathrm{~d}}$ & $24.88 \pm 2.24$ & $19.76 \pm 0.18$ & $19.74 \pm 0.30$ \\
$\mathrm{E}_{\mathrm{a}} / \mathrm{R}\left(\mathrm{k}_{\mathrm{d}}\right)$ & $9944 \pm 687$ & $8360 \pm 57$ & $10,446 \pm 61$ \\
$\beta$ & $0.425 \pm 0.09$ & $0.117 \pm 0.07$ & $0.134 \pm 0.05$ \\
\hline
\end{tabular}

On the other side, Table 4 displays the kinetic parameters of the model for all the systems. It seems that the activation energies depend notably on the ketone statistical parameters, changing between 60 and $80 \mathrm{~kJ} / \mathrm{mol}$ for the ketalization and hydrolysis reactions in systems 1 and 3, and being in excess of $100 \mathrm{~kJ} / \mathrm{mol}$ for the less active system 2 (MEK or butanone). These results are, in any case, within the range of values observed in literature for the solketal system (system 1), which are between 56 and 127 $\mathrm{kJ} / \mathrm{mol}[17,41]$. In any case, temperature affects more deeply the reaction rate in the less active system than in the other two.

If considering the activity remaining at infinitum time ( $\beta$ ), as observed also in Section 3.3.3, acetone and solketal affect the catalyst activity in a lower degree than the other ketones and ketals, remaining almost $43 \%$ of the original activity after the progressive deactivation process. For MEK and cyclohexanone only $12-13 \%$ of the initial activity remains. A possible blockage due to the ketal and/or the ketone can be suggested in this case. It must be considered that higher amounts of isopropanol (almost twice as much as in system 1) were needed for system 2 and 3 to get a homogeneous system, indicating a more hydrophobic nature of MEK and cyclohexanone. A relatively hydrophobic solid could strongly adsorb such ketones (and even their ketals) with the subsequent blockage deactivation. 


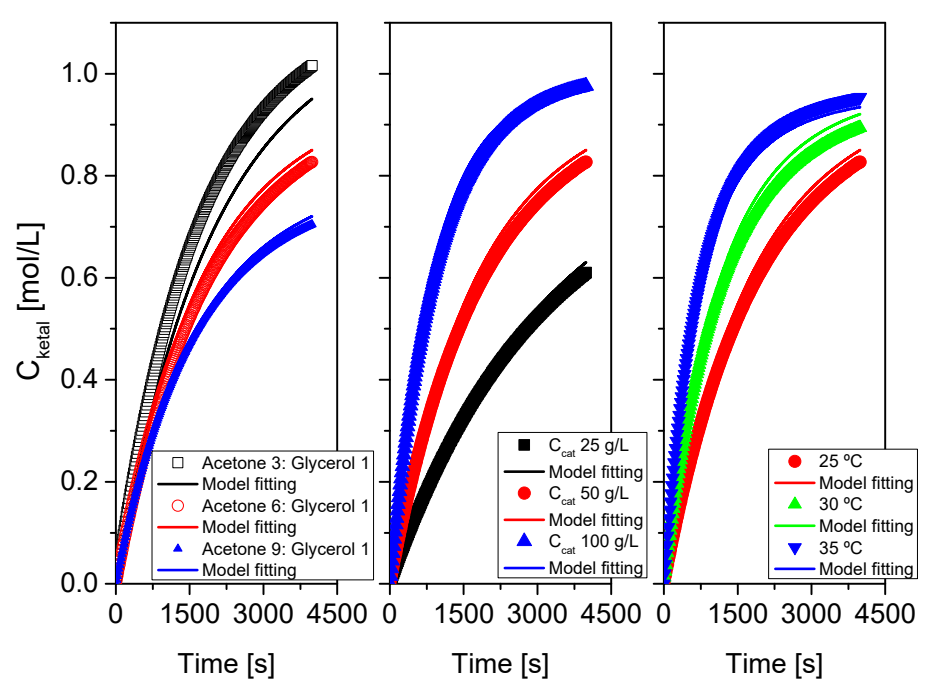

Figure 16. Fit of the proposed kinetic model to all data from system 1 (acetone+glycerol). Points correspond to the experimental data while lines show the fit of the model to such data.

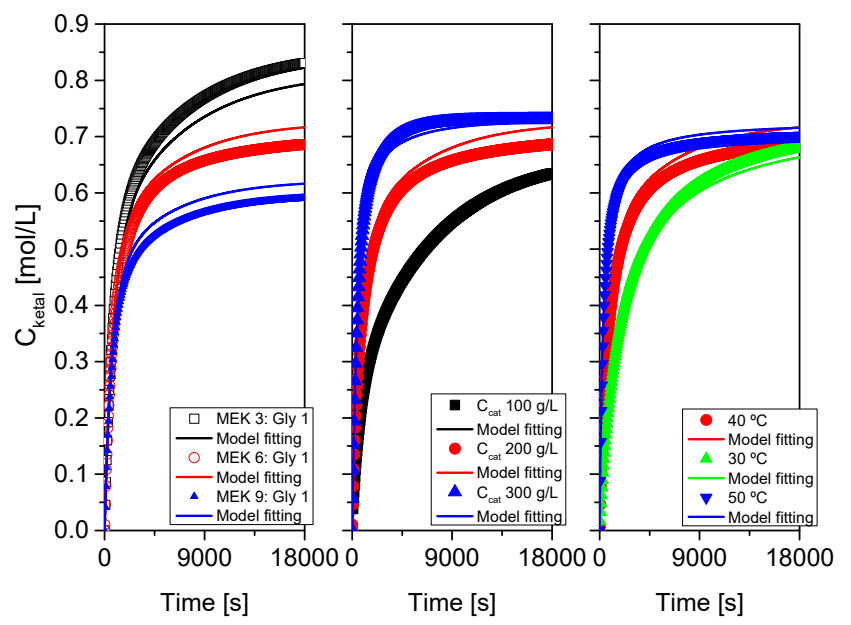

Figure 17. Fit of the proposed kinetic model to all data from system 2 (MEK+glycerol). Points correspond to the experimental data while lines show the fit of the model to such data.

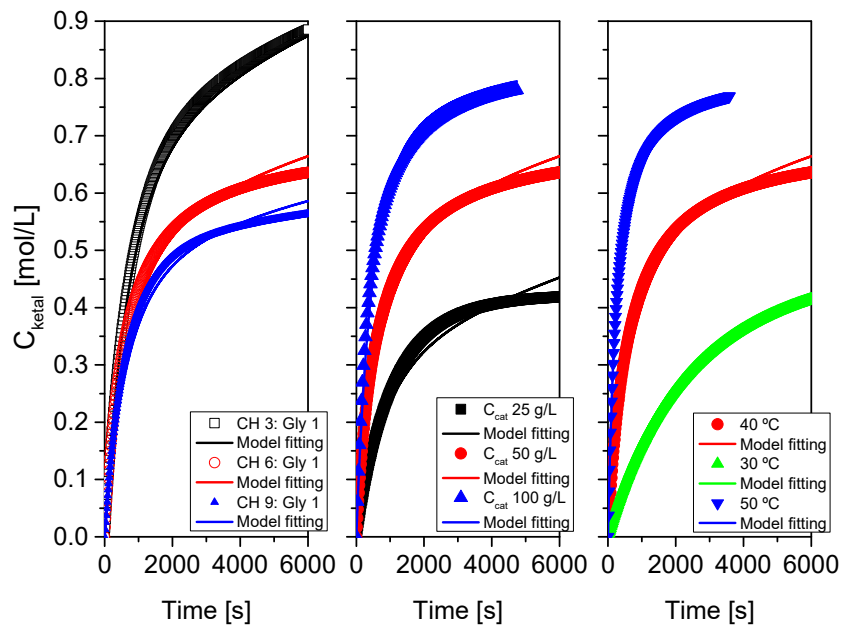

Figure 18. Fit of the proposed kinetic model to all data from system 3 (cyclohexanone+glycerol). Points correspond to the experimental data while lines show the fit of the model to such data. 
All kinetic parameters have narrow error intervals (low standard errors) at 95\% confidence, regardless of the reaction system being considered. Therefore, considering all physical and statistical criteria, the kinetic model here proposed, in spite of its simplicity, can be fitted adequately to a wide experimental range for the three systems.

Finally, Table 5 shows the estimated values of the kinetic constants and parameters from the minimal and maximal temperature values of the range studied here. It can be appreciated that, as observed with the initial reaction rate analysis, the ketalization and hydrolysis reactions for cyclohexanone and acetone proceed at a much faster rate than the one of MEK. Ketalization proceeds much faster at higher temperatures in all cases, but the hydrolysis reaction accelerates considerably with the temperature, even more than the other reactions. Thus, it seems that low temperatures are better, from this perspective, to obtain more ketal. On the other hand, although the catalyst deactivates less when acetone is used, it deactivates at a much faster rate. This deactivation is difficult to assign to a blockage of the pores due to either acetone or solketal (ketal 1), both very soluble in the washing solvent (acetone), so it should be adscribed to leakage of acid centers that are solvated in a relatively polar environment or to glycerol fouling of the pores.

Table 5. Estimated kinetic parameters for the model fitted to all data from acetone (system 1), MEK or butanone (system 2) and cyclohexanone (system 3) ketalization reactions with glycerol at the higher and lower temperature values within the range under study.

\begin{tabular}{lcccccc}
\hline Parameter & \multicolumn{2}{c}{ System 1 } & \multicolumn{2}{c}{ System 2 } & \multicolumn{2}{c}{ System 3 } \\
\hline $\mathrm{T}\left({ }^{\circ} \mathrm{C}\right)$ & 25 & 50 & 25 & 50 & 25 & 50 \\
$\mathrm{~T}(\mathrm{~K})$ & 298.16 & 323.16 & 298.16 & 323.16 & 298.16 & 323.16 \\
$\mathrm{k}_{1}$ & $1.03 \times 10^{-6}$ & $7.93 \times 10^{-6}$ & $1.77 \times 10^{-7}$ & $1.60 \times 10^{-6}$ & $3.50 \times 10^{-7}$ & $9.35 \times 10^{-6}$ \\
$\mathrm{k}_{2}$ & $2.62 \times 10^{-6}$ & $2.38 \times 10^{-5}$ & $3.36 \times 10^{-7}$ & $5.05 \times 10^{-6}$ & $2.41 \times 10^{-7}$ & $1.34 \times 10^{-5}$ \\
$\mathrm{k}_{\mathrm{d}}$ & $2.69 \times 10^{-2}$ & $2.44 \times 10^{-1}$ & $2.14 \times 10^{-4}$ & $1.90 \times 10^{-3}$ & $2.54 \times 10^{-4}$ & $2.22 \times 10^{-3}$ \\
$\beta$ & 0.425 & 0.425 & 0.134 & 0.134 & 0.117 & 0.117 \\
\hline
\end{tabular}

\section{Conclusions}

Ketals from glycerol are considered potential oxygenates to be used in fuel formulation. Considering the TOF, $1 \mathrm{~h} \mathrm{HCl}$ activated smectite $\mathrm{AC}$ is a good ketalization catalyst for the reaction of glycerol and several acyclic and cyclic ketones, even if it undergoes a first-order partial deactivation. During such activation, the original smectite $\mathrm{RC}$ porosity increases while its content in $\mathrm{Fe}, \mathrm{Mg}, \mathrm{K}$ and $\mathrm{Al}$ decreases, with a concomitant increase of the $\mathrm{SiO}_{2}$ component. Kinetic studies performed for the ketalization of glycerol with acetone (system 1), MEK (system 2), and cyclohexanone (system 3) led to a reversible kinetic model with elemental ketalization and hydrolysis reactions and partial first order deactivation. The models were adequate for a wide range of catalyst concentration, temperature and ketone to glycerol molar ratios.

Author Contributions: Conceptualization, A.B., N.M., E.S., N.B. and M.L.; Data curation, M.L.; Formal analysis, N.B. and M.L.; Funding acquisition, E.S. and N.B.; Investigation, S.A., J.G. and A.B.; Methodology, S.A., J.G., E.S., N.B. and M.L.; Resources, M.L.; Supervision, A.B., N.M., E.S., N.B. and M.L.; Writing-original draft, S.A. and M.L.; Writing-review \& editing, A.B., N.M., N.B. and M.L.

Acknowledgments: Tunis-El Manar University is gratefully acknowledged for financial support. Also, a very special gratitude goes out to the Spanish Ministry of Science and Innovation and the Department of Chemical Engineering and Materials, Faculty of Chemistry, Complutense University of Madrid. We are really indebted to Angeles Blanco, from the Department of Chemical Engineering and Materials of the Complutense University of Madrid, for her scientific support through fruitful discussions and for providing the FTIR equipment here employed for the kinetic experiments. The scientific support of Prof. Helena de la Fuente and Prof. Ruben Miranda is also gratefully acknowledged.

Conflicts of Interest: The authors declare no conflict of interest. 


\section{References}

1. García, E.; Laca, M.; Pérez, E.; Garrido, A.; Peinado, J. New Class of Acetal Derived from Glycerin as a Biodiesel Fuel Component. Energy Fuels 2008, 22, 4274-4280. [CrossRef]

2. Reddy, P.S.; Sudarsanam, P.; Mallesham, B.; Raju, G.; Reddy, B.M. Acetalisation of glycerol with acetone over zirconia and promoted zirconia catalysts under mild reaction conditions. J. Ind. Eng. Chem. 2011, 17, 377-381. [CrossRef]

3. Ilgen, O.; Yerlikaya, S.; Akyurek, F.O. Synthesis of solketal from glycerol and acetone over amberlyst-46 to produce an oxygenated fuel additive. Period. Polytech. Chem. Eng. 2017, 61, 144-148. [CrossRef]

4. Cornejo, A.; Barrio, I.; Campoy, M.; Lázaro, J.; Navarrete, B. Oxygenated fuel additives from glycerol valorization. Main production pathways and effects on fuel properties and engine performance: A critical review. Renew. Sustain. Energy Rev. 2017, 79, 1400-1413. [CrossRef]

5. Esteban, J.; Ladero, M.; Fuente, E.; Blanco, Á.; García-Ochoa, F. Experimental and modelling approach to the catalytic coproduction of glycerol carbonate and ethylene glycol as a means to valorise glycerol. J. Taiwan Inst. Chem. Eng. 2016, 63, 89-100. [CrossRef]

6. Abreu, T.H.; Meyer, C.I.; Padró, C.; Martins, L. Acidic V-MCM-41 catalysts for the liquid-phase ketalization of glycerol with acetone. Microporous Mesoporous Mater. 2019, 273, 219-225. [CrossRef]

7. Chaminand, J.; Djakovitch, L.; Gallezot, P.; Marion, P.; Pinel, C. Glycerol hydrogenolysis on heterogeneous catalysts. Green Chem. 2004, 6, 359-361. [CrossRef]

8. Akiyama, M.; Sato, S.; Takahashi, R.; Inui, K.; Yokota, M. Dehydration-hydrogenation of glycerol into 1,2-propanediol at ambient hydrogen pressure. Appl. Catal. A Gen. 2009, 371, 60-66. [CrossRef]

9. García-Sancho, C.; Cecilia, J.A.J.M.; Mérida-Robles, J.; Santamaría González, R.; Moreno-Tost, A.; Maireles-Torres, P. Effect of the treatment with $\mathrm{H}_{3} \mathrm{PO}_{4}$ on the catalytic activity of $\mathrm{Nb}_{2} \mathrm{O}_{5}$ supported on Zr-doped mesoporous silica catalyst. Case study: Glycerol dehydration. Appl. Catal. B Environ. 2018, 221, $158-168$.

10. Zhan, T.; Liu, W.; Teng, J.; Yue, C.; Li, D.; Wang, S.; Tan, H.; Yue, C. Selective oxidation of glycerol to tartronic acid over $\mathrm{Pt} / \mathrm{N}$-doped mesoporous carbon with extra framework magnesium catalysts under base-free conditions. Chem. Commun. 2019, 55, 2620-2623. [CrossRef]

11. Esteban, J.; Fuente, E.; Blanco, A.; Ladero, M.; García-Ochoa, F. Phenomenological kinetic model of the synthesis of glycerol carbonate assisted by focused beam reflectance measurements. Chem. Eng. J. 2015, 260, 434-443. [CrossRef]

12. Liu, J.; Zhang, Z.; Zhang, P.; Yang, B. On the kinetics of multiphase etherification of glycerol with isobutene. Chem. Eng. J. 2019, 375, 122037. [CrossRef]

13. Miranda, C.; Urresta, J.; Cruchade, H.; Tran, A.; Benghalem, M.; Astafan, A.; Gaudin, P.; Daou, T.; Ramírez, A.; Pouilloux, Y.; et al. Exploring the impact of zeolite porous voids in liquid phase reactions: The case of glycerol etherification by tert-butyl alcohol. J. Catal. 2018, 365, 249-260. [CrossRef]

14. Aghbashlo, M.; Tabatabaei, M.; Jazini, H.; Ghaziaskar, H.S. Exergoeconomic and exergoenvironmental co-optimization of continuous fuel additives (acetins) synthesis from glycerol esterification with acetic acid using Amberlyst 36 catalyst. Energy Convers. Manag. 2018, 165, 183-194. [CrossRef]

15. Ratchadapiban, K.; Praserthdam, P.; Tungasmita, D.N.; Tangku, C.; Anutrasakda, W. Effect of Surface Modifications of SBA-15 with Aminosilanes and 12-Tungstophosphoric Acid on Catalytic Properties in Environmentally Friendly Esterification of Glycerol with Oleic Acid to Produce Monoolein. Catalysts 2018, 8, 360. [CrossRef]

16. Chamack, M.; Mahjoub, A.R.; Akbari, A. Zirconium-modified mesoporous silica as an efficient catalyst for the production of fuel additives from glycerol. Catal. Commun. 2018, 110, 1-4. [CrossRef]

17. Esteban, J.; Ladero, M.; García-Ochoa, F. Kinetic modelling of the solventless synthesis of solketal with a sulphonic ion exchange resin. Chem. Eng. J. 2015, 269, 194-202. [CrossRef]

18. Timofeeva, M.N.; Panchenko, V.N.; Krupskaya, V.V.; Gil, A.; Vicente, M.A. Effect of nitric acid modification of montmorillonite clay on synthesis of solketal from glycerol and acetone. Catal. Commun. 2017, 90, 65-69. [CrossRef]

19. Len, C.; Luque, R. Continuous flow transformations of glycerol to valuable products: An overview. Sustain. Chem. Process. 2014, 2, 1. [CrossRef] 
20. Aghbashlo, M.; Tabatabaei, M.; Hosseinpour, S.; Rastegari, H.; Ghaziaskar, H.S. Multi-objective exergy-based optimization of continuous glycerol ketalization to synthesize solketal as a biodiesel additive in subcritical acetone. Energy Convers. Manag. 2018, 160, 251-261. [CrossRef]

21. Samoilov, V.; Maximov, A.; Stolonogova, T.; Chernysheva, E.; Kapustin, V.; Karpunina, A. Glycerol to renewable fuel oxygenates. Part I: Comparison between solketal and its methyl ether. Fuel 2019, 249, 486-495.

22. Fatimah, I.; Sahroni, I.; Fadillah, G.; Musawwa, M.M.; Mahlia, T.M.I.; Muraza, O. Glycerol to Solketal for Fuel Additive: Recent Progress in Heterogeneous Catalysts. Energies 2019, 12, 2872. [CrossRef]

23. Namazifar, Z.; Saadati, F.; Miranbeigi, A.A. Synthesis and characterization of novel phenolic derivatives with the glycerol ketal group as an efficient antioxidant for gasoline stabilization. New J. Chem. 2019, 43, 10038-10044. [CrossRef]

24. Nobre, P.C.; Vargas, H.A.; Jacoby, C.G.; Schneider, P.H.; Casaril, A.M.; Savegnago, L.; Schumacher, R.F.; Lenardão, E.J.; Ávila, D.S.; Rodrigue, L.B.L.; et al. Synthesis of enantiomerically pure glycerol derivatives containing an organochalcogen unit: In vitro and in vivo antioxidant activity. Arab. J. Chem. 2017, in press. [CrossRef]

25. Talebian-Kiakalaieh, A.; Amin, N.A.S.; Najaafi, N.; Tarighi, S. A Review on the Catalytic Acetalization of Bio-renewable Glycerol to Fuel Additives. Front. Chem. 2018, 6, 573. [CrossRef]

26. Deutsch, J.; Martin, A.; Lieske, H. Investigations on heterogeneously catalysed condensations of glycerol to cyclic acetals. J. Catal. 2007, 245, 428-435. [CrossRef]

27. da Silva, C.X.; Gonçalves, V.L.; Mota, C.J. Water-tolerant zeolite catalyst for the acetalisation of glycerol. Green Chem. 2009, 11, 38-41. [CrossRef]

28. Manjunathan, P.; Maradur, S.P.; Halgeri, A.; Shanbhag, G.V. Room temperature synthesis of solketal from acetalization of glycerol with acetone: Effect of crystallite size and the role of acidity of beta zeolite. J. Mol. Catal. A Chem. 2015, 396, 47-54. [CrossRef]

29. Nagendrappa, G. Organic synthesis using clay and clay-supported catalysts. Appl. Clay Sci. 2011, 53, $106-138$. [CrossRef]

30. Besbes, N.; Jellali, H.; Pale, P.; Srasra, E.; Efrit, M.L. Transformations de N-acylaziridines catalysées par des supports à base de silice et d'alumine: Une élucidation mécanistique. C. R. Chim. 2010, 13, 358-364. [CrossRef]

31. Besbes, N.; Jellali, H.; Pale, P.; Efrit, M.L.; Srasra, E. Srasra, Isomerisation Catalysee Par le Gel de Silice et L'argile Activee de N-Acyl-2,2-Dimethylaziridines: Approche Mecanistique. Phosphorus Sulfur Silicon Relat. Elem. 2010, 185, 883-889. [CrossRef]

32. Mnasri, S.; Besbes, N.; Frini-Srasra, N.; Srasra, E. Étude de l'activité catalytique des argiles pontées aluminium, zirconium et cérium dans la synthèse du 2,2-diméthyl-1,3-dioxolane. Comptes Rendus Chim. 2012, 15, 437-443. [CrossRef]

33. Domínguez-Barroso, V.; Herrera, C.; Larrubia, M.Á.; González-Gil, R.; Cortés-Reyes, M.; Alemany, L.J. Continuous-Flow Process for Glycerol Conversion to Solketal Using a Brönsted Acid Functionalized Carbon-Based Catalyst. Catalysts 2019, 9, 609. [CrossRef]

34. Cornejo, A.; Campoy, M.; Barrio, I.; Navarrete, B.; Lazaro, J. Solketal production in a solvent-free continuous flow process: scaling from laboratory to bench size. React. Chem. Eng. 2019, 4, 1803-1813. [CrossRef]

35. Hagui, W.; Essid, R.; Amri, S.; Fares, N.; Khabbouchi, M.; Tabbene, O.; Limam, F.; Srasra, E.; Besbes, N. Acid-activated clay as heterogeneous and reusable catalyst for the synthesis of bioactive cyclic ketal derivatives. Turk. J. Chem. 2019, 43, 435-451. [CrossRef]

36. Merayo, N.; Hermosilla, D.; Negro, C.; Blanco, A. On-line FTIR as a novel tool to monitor Fenton process behavior. Chem. Eng. J. 2013, 232, 519-526. [CrossRef]

37. He, B.; Ren, Y.; Cheng, Y.; Li, J. Deactivation and in Situ Regeneration of Anion Exchange Resin in the Continuous Transesterification for Biodiesel Production. Energy Fuels 2012, 26, 3897-3902. [CrossRef]

38. Reddy, C.R.; Bhat, Y.; Nagendrappa, G.; Prakash, B.J. Brønsted and Lewis acidity of modified montmorillonite clay catalysts determined by FT-IR spectroscopy. Catal. Today 2009, 141, 157-160. [CrossRef]

39. Esteban, J.; García-Ochoa, F.; Ladero, M. Solventless Synthesis of Solketal with Commercially Available Sulfonic Acid Based Ion Exchange Resins and Their Catalytic Performance. Green Process. Synth. 2017, 6, 79-89. [CrossRef] 
40. Qian, J.; Qiu, M.; Zeng, Z.; Xue, W.; Xu, J. Cation-Exchange Resin Catalyzed Ketalization Reaction of Cyclohexanone with 1,4-Butanediol: Thermodynamics and Kinetics. Ind. Eng. Chem. Res. 2018, 57, 4841-4847. [CrossRef]

41. Nanda, M.R.; Yuan, Z.; Qin, W.; Ghaziaskar, H.S.; Poirier, M.-A.; Xu, C.C. Thermodynamic and kinetic studies of a catalytic process to convert glycerol into solketal as an oxygenated fuel additive. Fuel 2014, 117, 470-477. [CrossRef]

42. Sirijaruphan, A.; Goodwin, J.G.; Rice, R.W. Investigation of the initial rapid deactivation of platinum catalysts during the selective oxidation of carbon monoxide. J. Catal. 2004, 221, 288-293. [CrossRef]

43. Rodríguez, J.C.; Peña, J.A.; Monzón, A.; Hughes, R.; Li, K. Kinetic modelling of the deactivation of a commercial silica-alumina catalyst during isopropylbenzene cracking. Chem. Eng. J. Biochem. Eng. J. 1995, 58, 7-13. [CrossRef]

(C) 2019 by the authors. Licensee MDPI, Basel, Switzerland. This article is an open access article distributed under the terms and conditions of the Creative Commons Attribution (CC BY) license (http://creativecommons.org/licenses/by/4.0/). 